\title{
Revision of the genus Diaphorocera Heyden, 1863 (Coleoptera, Meloidae, Cerocomini)
}

\author{
Federica Turco and Marco A. Bologna \\ Dipartimento di Biologia, Università “Roma Tre”, viale Marconi 446-00146Roma, Italy,turco@uniroma3.it, bologna@ \\ uniroma3.it
}

Key words: Coleoptera, Meloidae, Diaphorocera, taxonomy, phylogeny, morphology, faunistics, biogeography, Palaearctic region.

\begin{abstract}
Diaphorocera, a Saharo-Sindian genus belonging to the tribe Cerocomini, is revised and a new synonymy is proposed. A cladistic classification is proposed as well, on a set of adult morphological characters. The available bionomical records, both original and from literature, concerning phenology, elevation, habitat preference, and host plants, are summarised. Adult morphology of all species is described and figured, the catalogue of localities with maps of distribution is reported, and a biogeographical analysis is proposed.
\end{abstract}

\section{Contents}

Introduction 63

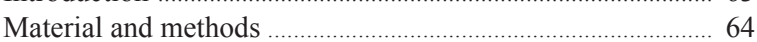

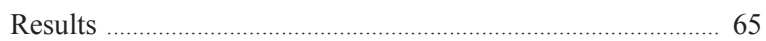

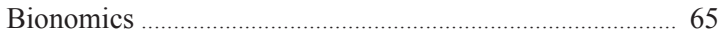

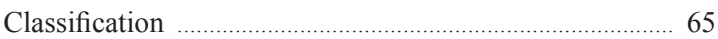

Key to the species of Diaphorocera ……………....................... 67

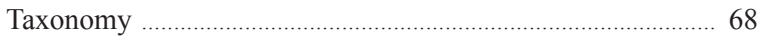

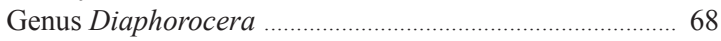

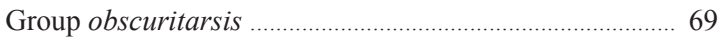

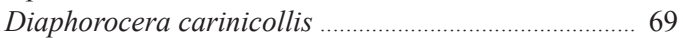

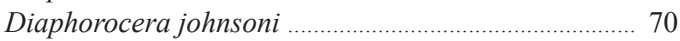

Diaphorocera obscuritarsis .......................................... 71

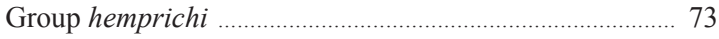

Diaphorocera chrysoprasis ............................................ 73

Diaphorocera hemprichi ................................................ 75

Diaphorocera promelaena ............................................. 76

Diaphorocera sicardi ................................................. 78

Diaphorocera peyerimhoffi ........................................... 78

Biogeography ....................................................................... 80

Acknowledgements ............................................................... 83

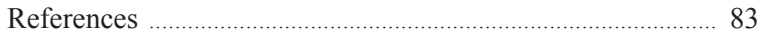

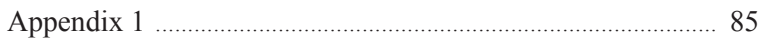

Appendix 2 ………………………………………………....... 85

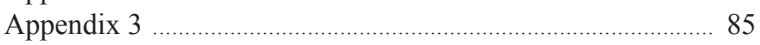

\section{Introduction}

The family Meloidae (Coleoptera, Tenebrionoidea) was recently revised cladistically (Bologna and Pinto, 2001) and four subfamilies were recognised: Eleticinae, Meloinae, Tetraonycinae and Nemognathinae (Pinto and Bologna, 1999; Bologna and Pinto, 2002). Blister beetles are phytophagous, feeding usually on leaves and/or flowers of several plant families, and are characterised by cantharidin production and hypermetamorphic development, except in the primitive subfamily Eleticinae (Pinto et al., 1996; Bologna et al., 2001). Larvae feed on the provisions and larvae of Hymenoptera Apoidea, or on grasshopper (Acridoidea) eggs (Bologna, 1991).

Within the subfamily Meloinae, our interest was recently addressed to the Old World tribe Cerocomini, which is composed of five genera (Bologna and Pinto, 2002): Cerocoma Geoffroy, 1762 (about 27 species), Diaphorocera Heyden, 1863 (8 spp.), Anisarthrocera Semenov, 1895 (2 spp.), Rhampholyssa Kraatz, 1863 (2 spp.) and Rhampholyssodes Kaszab, 1983 (1 sp.). Bologna and Pinto (2001) used larval and adult characters to reconstruct the phylogeny of Meloidae, but the placement of the tribe Cerocomini, then represented only by Cerocoma schreberi, remained unresolved. The authors recognised two larval synapomorphies for the tribe, then confirmed for other species of Cerocoma (Di Giulio et al., 2002) and also for Diaphorocera chrysoprasis (Turco et al., 2006). Moreover, the monophyly of the tribe is strongly supported by adult synapomorphies, as the position of antennae (sockets distant from eyes, placed below or on the frontal suture), the epigamic modifications of male head, antennae, maxillary palpi and fore legs, the labrum elongate 
and longitudinally furrowed or carinate, the shape of mouthparts and the endophallic structure (Bologna, 1991; Turco et al., 2003).

The biology of the tribe is poorly known with the exception of some notes on host plants (Bologna, 1991), on sexual behaviour of the genus Cerocoma (Turco et al., 2003), and on larval hosts of few Cerocoma species (see Bologna, 1991 for a synthesis). Pre-imaginal stages of Cerocomini are known only for six species of Cerocoma (Di Giulio et al., 2002 for a review; Turco and Bologna, unpublished), and one Diaphorocera (Turco et al., 2006). Eggs are laid in holes dug by the female in the ground as in other Meloinae, and the first instar larvae ("triungulins") are not phoretic, actively reaching the host's nest where they develop to adult stage. As far as is known, triungulins feed on larvae and honey or on eggs and food stored by Hymenoptera Aculeata (Bologna, 1991 for a review).

After the first studies on the larval morphology (Di Giulio et al., 2002; Turco et al., 2006), our project was addressed to the revision of the tribe Cerocomini as a whole. The present paper is focused on the study of the genus Diaphorocera; another contribution is addressed to the classification of the five genera and to the revision of Anisarthrocera, Rhampholyssa and Rhampholyssodes (Turco and Bologna, unpublished); the third study will be devoted to the revision of the more speciose genus Cerocoma (Turco and Bologna, unpublished).

The genus Diaphorocera is a typical Saharo-Sindian element, distributed in the whole Northern Africa, southern Middle East (Palestine and Israel), Arabian Peninsula, and in southern Iran. This genus was never revised: Bedel (1895) published the first key to the species, updated by Kaszab (1951; taken up by Dvořak, 1989), after which one new species and one new subspecies were described (Kocher, 1954; Kaszab, 1983).

Table 1. Types and other specimens examined.

\begin{tabular}{llc}
\hline Species & $\begin{array}{l}\text { Types and } \\
\text { location }\end{array}$ & $\begin{array}{r}\text { Other } \\
\text { specimens }\end{array}$ \\
\hline D. carinicollis & lectotype, 5 paralectotypes MNHN & 1 \\
D. chrysoprasis & & 90 \\
D. hemprichi hemprichi & 4 paratypes HNHM & 53 \\
D. hemprichi saudita & 3 paratypes HNHM & 47 \\
D. johnsoni & 8 \\
D. kerimii (syn. of D. chrysoprasis) holotype MCSN & \\
D. obscuritarsis & holotype, 12 paratypes MNHN, HNHM & 76 \\
D. obscuritarsis var. ruficornis & syntype MNHN & \\
D. peyerimhoffi & holotype, 'allotype', 1 'cotype' ISR & 17 \\
D. promelaena & 9 paratypes HNHM & 73 \\
D. sicardi & holotype MNHN & 4 \\
\hline
\end{tabular}

\section{Material and methods}

During our field researches we obtained ecological information on host plants and phenology on three species (D. chrysoprasis, D. hemprichi of both subspecies, D. johnsoni). We reared these species and we obtained the triungulin of $D$. chrysoprasis, described in a separate paper (Turco et al., 2006).

For the taxonomical study we examined 396 specimens representing all the Diaphorocera species, with at least one male of each species, including typical material, as reported in Table 1. The examined specimens are preserved in the following collections (associated acronyms reported in the text): $\mathrm{CB}=\mathrm{M}$. A. Bologna coll., Università "Roma Tre", Roma; CBA = J. Batelka coll., Prague; CK = S. Krejcik coll., Unicov, Czech Republic; CP = J. D. Pinto coll., University of California, Riverside; CR = J. C. Ringenbach coll., Paris; CS = D. Sechi coll., Cagliari; ISR = Institut Sciéntifique, Rabat; UCD = University of California Museum, Davis; $\mathrm{MCSN}=$ Museo Civico di Storia Naturale G. Doria, Genova; MHNG = Muséum d'Histoire Naturelle, Genève; MNHN = Muséum National d'Histoire Naturelle, Paris; MVE = Museo di Storia Naturale, Venezia; HNHM = Hungarian Natural History Museum, Budapest; OUM = Oxford University Museum, Oxford.

For the phylogenetical analysis of the eight species of Diaphorocera we used the software PAUP 4.0 (Swofford, 2002) and 24 adult characters available for all species, selected from a larger set previously identified; character 24 was not observed in $D$. peyerimhoff because the dissection of types was not possible. The character matrix with the related list are given in Appendices 1 and 2. According to Bologna and Pinto (2002), the single taxon constrained as outgroup is "Anisarthrocera" semirufa (Fairmaire, 1882) (see "Classification"). Autapomorphic characters were utilized for the diagnoses and key only. As expected, characters displayed some homoplasies, as indicated by relatively low consistency index (CI) (Appendix 3). Both binary and multistate characters were employed, all elaborated as unordered and equally weighted, and processed by the branch-and-bound algorithm using 'parsimony' as optimality criterion and the 'furthest' addition sequence option. The accelerated transforma- 
tion algorithm (ACCTRAN) was used to optimize characters on cladograms. Confidence levels were assessed using Bootstrap Analysis and results were compared by generating a strict consensus cladogram.

\section{Results}

\section{Bionomics}

All the species live in eremic habitats, both on dunes or stony desert (Fig. 1). Species of this genus are strictly diurnal, and adult occurrence is primarily restricted to spring, as summarised in Table 2. All the species seem to be distributed at low elevation, from sea level to about $200 \mathrm{~m}$ a.s.l., with a single record of D. obscuritarsis at $1200 \mathrm{~m}$ a.s.l. in southern Morocco.

Adults feed on pollen of several plant families; all personal and literature records are summarised in Table 2. Thanatosis was observed in the field in D. hemprichi, $D$. johnsoni and D. chrysoprasis. In this genus sexual dimorphism is evident mostly on head, antennae, and sometimes also on fore tibiae, but courtship behaviour has never been studied, and we only quickly observed on flowers the dorsal and the subsequent linear phases of $D$. chrysoprasis copulation. As previously indicated, the larval hosts and the pre-imaginal development are unknown, except the triungulin of $D$. chrysoprasis (Turco et al., 2006).

\section{Classification}

This genus was described by Heyden (1863) to include D. hemprichi from Egypt, but in the same year a second species was described by Fairmaire (1863) from the opposite side of Sahara, and Bedel (1895) evidenced definitively the Saharan distribution of this genus. Subsequently other representatives were found also in the Arabian peninsula and South Iran, enlarging its range, which is now similar to that of other eremic genera of animals and plants.

The phylogenetic relationships of Diaphorocera within Cerocomini were never defined and are the object of a separate contribution (Turco and Bologna, unpublished). Larval features of Cerocomini are until now

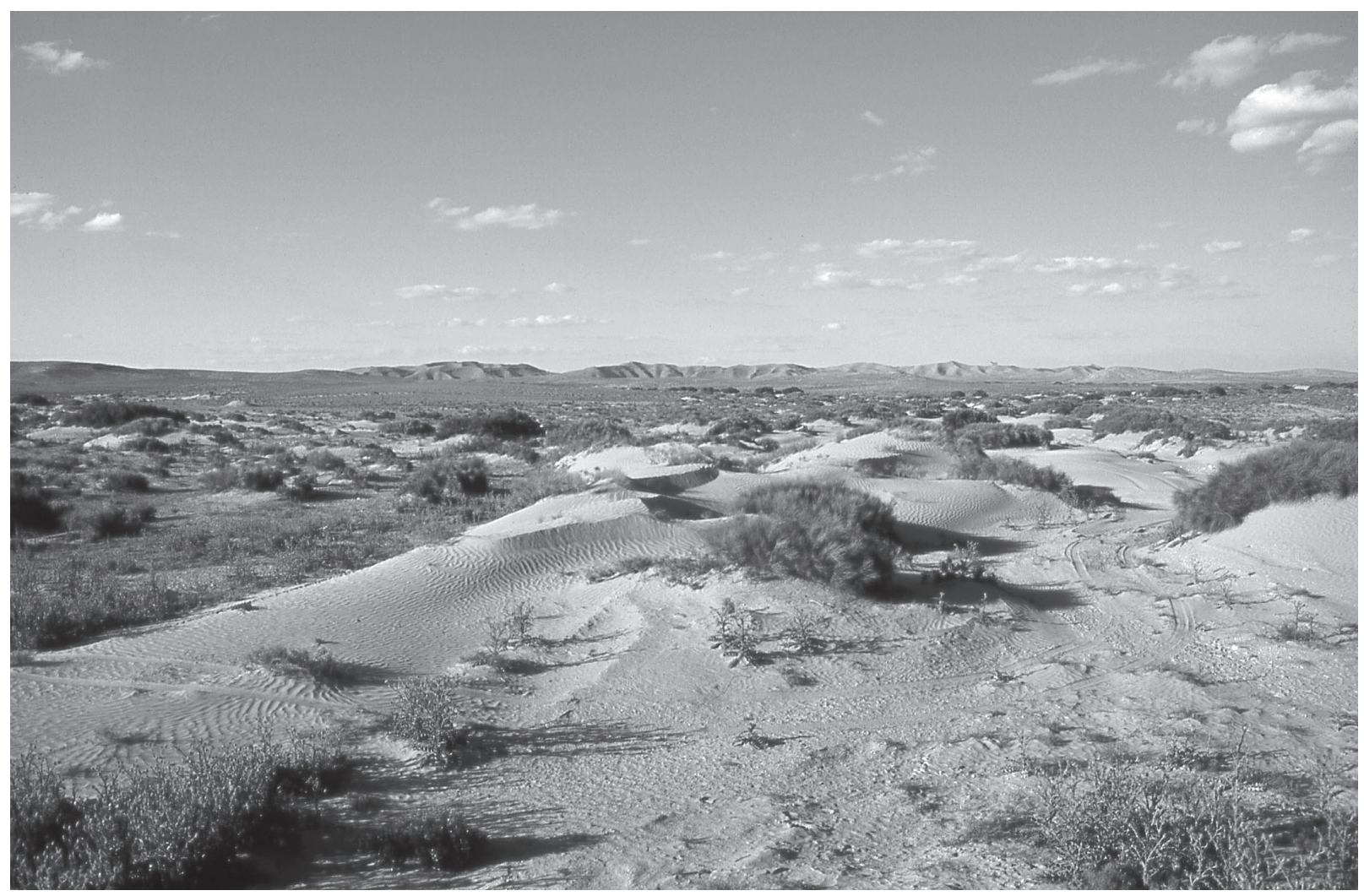

Fig. 1. Habitat of D. chrysoprasis, Tunisia, $10 \mathrm{~km} \mathrm{SW}$ of Tozeur on road P3. 
Table 2. Ecological information on phenology and host plants of adults. Phenology in brackets indicates eccentric records. Ap = Apiaceae; As = Asteraceae; $\mathrm{B}=$ Brassicaceae $\mathrm{F}=$ Fabaceae; $\mathrm{R}=$ Resedaceae $\mathrm{T}=$ Tamaricaceae $\mathrm{Z}=$ Zygophyllaceae.

\begin{tabular}{|c|c|c|}
\hline Species & Phenology & Host plants \\
\hline D. carinicollis & late April - May & \\
\hline D. chrysoprasis & April - May (February) & Chrysanthemum coronarium (As) \\
\hline D. hemprichi & March - May (July, November) & $\begin{array}{l}\text { Senecio glaucus, Asteriscus graveolens, Anvillea radiata (As); Eremobium } \\
\text { aegyptiacum }(\mathrm{B}) ; \text { Reseda arabica }(\mathrm{R}) ; \text { Tribulus omanense, Zygophyllum } \\
\text { mandavillei }(\mathrm{Z})\end{array}$ \\
\hline D. johnsoni & March - May & Zygophyllum mandavillei $(\mathrm{Z})$ \\
\hline D. obscuritarsis & April - May (February) & $\begin{array}{l}\text { Eruca aurea, Farsetia linearis }(\mathrm{B}) ; \text { Amni visnaga }(\mathrm{Ap}) ; \text { Reseda lutea }(\mathrm{R}) \text {; } \\
\text { Tamarix ramossissima }(\mathrm{T})\end{array}$ \\
\hline D. peyerimhoffi & middle June & \\
\hline D. promelaena & April - early June & Retama sp. (F) \\
\hline D. sicardi & April - May & \\
\hline
\end{tabular}

uninformative, because of their scarcity, homogeneity, and also because pertinent to only two genera.

Kaszab $(1951,1969,1983)$ divided the genera on the base of the number of antennomeres, considering correctly the reduction as a derived condition, but he did not evaluate other derived features as those of aedeagus, fore tibiae, etc. The basic number of antennomeres of Meloidae is 11, but the reduction is common particularly in several genera of the tribe Mylabrini. Two genera of Cerocomini have 11 antennomeres, as a primitive condition: Diaphorocera and Anisarthrocera. Two other genera, namely Cerocoma and Rhampholyssodes, have 9-segmented antennae, and a fifth genus, Rhampholyssa, has 8-segmented antennae.

Bologna and Pinto (2002) supposed the separation of Anisarthrocera from Diaphorocera could be doubtful. Actually, Diaphorocera is distinct, but its relationships may be looked for examining the Anisarthrocera-complex. In fact, this last genus, considered temporarily as monophyletic by Bologna and Pinto (2002), is actually polyphyletic (Turco and Bologna, unpusblished). It includes $A$. batesi Marseul, 1872, a polytypic species from Iran and Arabia, which is greatly different from $A$. semirufa (Fairmaire, 1882) from N Somalia and a new Kenyan species, which probably belong to a new genus (Turco and Bologna, unpublished). These last two species have unmodified male fore tibiae, unlike $A$. batesi, and are slightly similar to Diaphorocera (see also Bologna, 1991), from which they differs at least for the single hook on both aedeagus and endophallus, in addition to the body colouration. Contrarily to Kaszab (1951), frontal calli are found, more or less developed, in both Anisarthrocera-complex and Diaphorocera and cannot be used to separate them.

Waiting for the phylogenetic revision of the tribe
(Turco and Bologna, unpublished), we consider Diaphorocera as a primitive genus of the tribe, together with Anisarthrocera s.str. and the new East African genus. Phenetically, this new genus seems more close to Diaphorocera than to Anisarthrocera.

Relationships among Diaphorocera species derived from the cladistic analysis, are summarised in a cladogram (Fig. 2), emerging from a matrix of 8 species (and the outgroup "Anisarthrocera" semirufa) $\times 24$ characters (Appendixes 1 and 2). This most parsimonious cladogram evidences three main lineages: one including 3 species, and the second including a single species, the last 4 species, subdivided in two minor lineages (see Table 3 for a list of synapomorphies). The main lineages represent three monophyletic groups of species recognised primarily by the shape of male fore tibiae and last antennomere:

a The obscuritarsis group: D. carinicollis, D. johnsoni, D. obscuritarsis, all with last male antennomere subquadrate and fore tibiae not modified. The first character could be considered an apotypic condition, because blister beetles and in particular other Cerocomini, have the last antennomere elongate. The second character is plesiotypic. Relationships among the species were not resolved by the cladistic (Fig. 2 ), but the bootstrap analysis distinguished one clade including $D$. obscuritarsis and $D$. carinicollis by a very low confidence value (24).

b The promelaena group: D. promelaena only, characterised by the last antennomere elongate as in the hemprichi group, but distinct because of a different derived condition of the male fore tibia, modified only distally, and by the integument partially black. The phylogenetic placement of this group seems to be close to the obscuritarsis group, even if supported by a relatively high consistency index (69). 


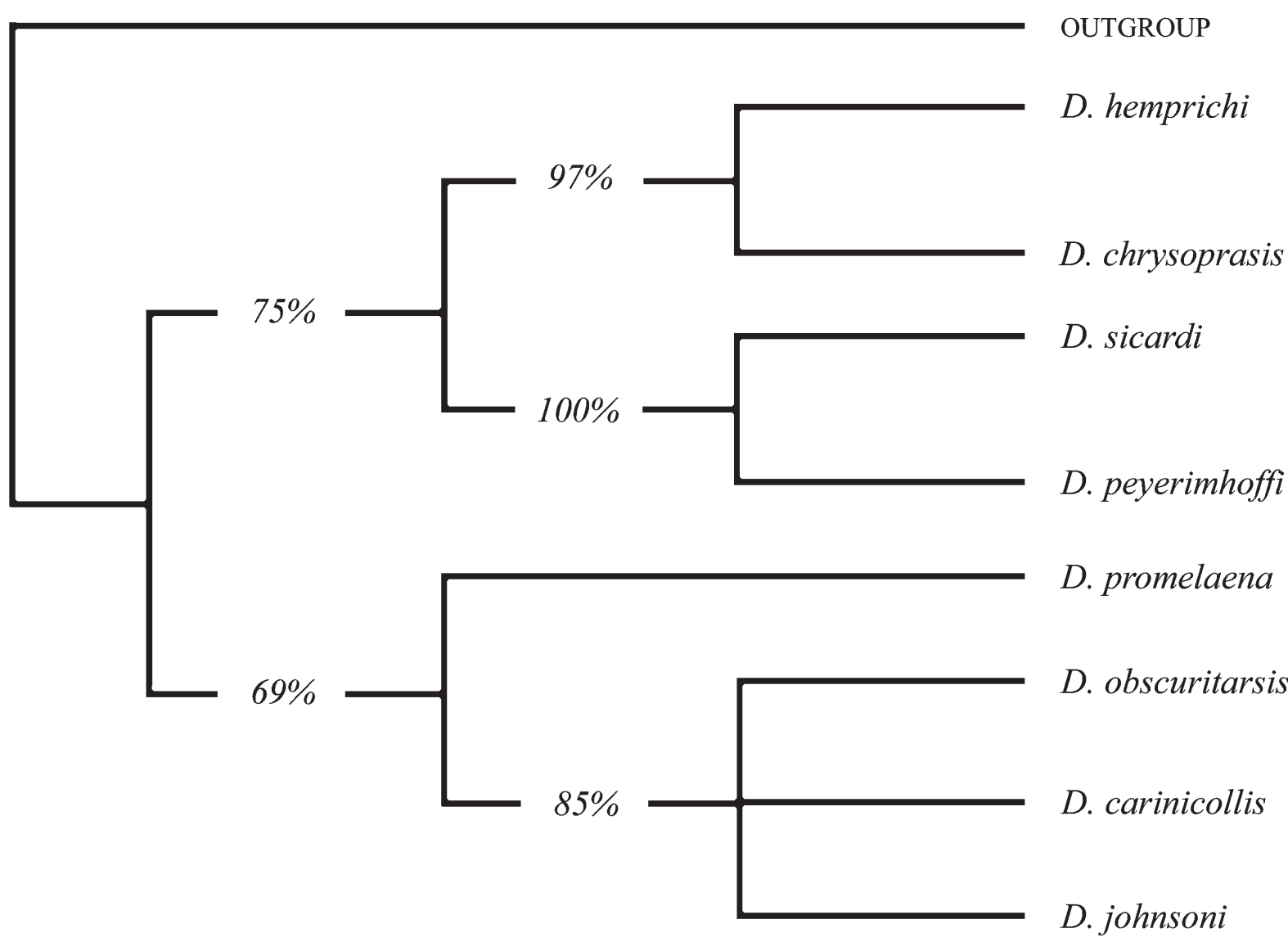

Fig. 2. Strict consensus tree of two cladograms using matrix in Appendix 1 (see Material and methods).

c The hemprichi group: D. chrysoprasis, D. hemprichi; D. sicardi, D. peyerimhoffi. All these species have the last antennomere elongate and fore tibiae variously modified (two different apotypic conditions). Relationships among the species appear clearly defined. In particular, the first two species have the fore tibiae greatly modified with a laminar expansion on the external side, extended to the whole length. On the other hand, D. sicardi and D. peyerimhoffi represent a very distinct West Saharan lineage, ex-

Table 3. List of synapomorphic characters defining monophyletic groups (see Appendix 2 for the definition of characters).

\begin{tabular}{ll}
\hline $\begin{array}{l}\text { (hemprichi-chrysoprasis- } \\
\quad \text { sicardi-peyerimhoffi) }\end{array}$ & $1,6,8,9,14$ \\
(hemprichi-chrysoprasis) & 2,20 \\
(sicardi-peyerimhoffi) & $13,15,16,17,20$ \\
(obscuritarsis-carinicollis-johnsoni) & $4,7,21$ \\
\hline
\end{tabular}

tremely supported by the cladistic analysis, characterised by some synapomorphies, as the modified frontal calli, the labrum dorsal structure, and the peculiar shape of male fore tibiae, only bulged in the basal third.

\section{Key to the species of Diaphorocera}

Male

1 Foretibiae simple. Antennomere XI subquadrate .. 2

- Foretibiae variously modified. Antennomere XI elongate 4

2 Two black and shiny lines on antennomere XI and one on antennomere $\mathrm{X}$ D. obscuritarsis

- Antennomeres X-XI without lines ............................ 3

3 Antennomere VII distinctly wider than VI and slightly narrower than VIII; antennomere I dark. Pronotum slender, anterior portion distinctly narrower than temples; anterior grooves only weakly 
developed. External margin of elytra only slightly sinuate D. johnsoni

- Antennomere VII only slightly wider than VI and as wide as VIII; antennomere I yellow. Pronotum robust, anterior portion only slightly narrower than temples; anterior grooves deep. External margin of elytra posteriorly greatly sinuate ................. D. carinicollis

4 Head, pronotum, abdomen and antennomere I black D. promelaena

- Head, pronotum, abdomen and antennomere I not black 5

5 Frontal calli with a dorsal keel anteriorly protruded and pointed; fore tibiae with a basal inflated expansion, without laminar expansions ... 6

- Frontal calli neither keeled nor anteriorly protruding; fore tibiae with a laminar expansion, at least on the external side, extended to the entire length of the tibia

6 Antennomeres VIII-XI with black lines and spots, anterior portion of X wide, that of VII obliquely truncate, that of IV deeply incised .......... D. sicardi

- Antennomeres VIII-XI without black lines and spots, anterior portion of $\mathrm{X}$ short and thin, that bilobate, that of IV largely incised ................. D. peyerimhoffi

7 Antennomere $\mathrm{X}$ about as wide as the length of XI, anterior portion slender and pointed at apex; IX about as wide as VIII

D. hemprichi

- Antennomere X distinctly narrower than the length of XI. Anterior portion of antennomere IX wide and apically truncate; IX narrower than VIII

D. chrysoprasis

\section{Female}

1 Antennomere XI subquadrate ....................................... 2

- Antennomere XI elongate ............................................. 4

2 Fore and middle tarsomeres IV-V dark, basal segments yellow; trochanters only slightly darkling ....

D. carinicollis

- Tarsomeres and trochanters dark, or fore tarsomere I light at base 3

3 Labrum completely dark; temples slightly diverging posteriad, maximum width of head on temples. Femurs and tibiae orange-red ........... D. obscuritarsis

- Labrum dark with the anterior margin orange; temples parallel, maximum width of head on eyes. Femurs and tibiae yellow D. johnsoni

4 Head and pronotum black D. promelaena

- Head and pronotum metallic 5

5 Coxae and trochanters black .......... D. peyerimhoffi

- Coxae metallic, green or bluish, trochanters yellow 6
6 Body blue, but fore coxae yellow ........... D. sicardi

- Body and fore coxae green metallic .......................... 7

7 Temples elongate, about as long as the eye length, with subparallel sides ........................ D. chrysoprasis

- Temples shorter than the eye length, narrowing evenly posteriad D. hemprichi

\section{Taxonomy}

Genus Diaphorocera Heyden, 1863

Diaphorocera Heyden, 1863: 126.

Type species. Diaphorocera hemprichi Heyden, 1863: 126 , by monotypy.

Diagnosis. The genus Diaphorocera is characterised, as other Cerocomini, by a marked sexual dimorphism. Several male characters do not represent generic synapomorphies but are present in most species of the genus, as the modifications of fore tibiae. Because of the number (11) of antennomeres, the metallic colouration of most part of body, the presence of two hooks on both aedeagus and endophallus, Diaphorocera is easily distinguishable from any other cerocomine meloid.

6-17 mm length. Head most commonly metallic, green or blue, in one species (D. promelaena) black, in some specimens with a red spot on frons. Labrum, mandibles, and maxillae very elongate, completely or partially orange; galeae fringed. Frons of males with two smooth calli, just behind the antennae, scarcely raised (D. johnsoni) to very distinct and keeled (D. sicardi, D. peyerimhoffi). Antennae orange or with antennomere I metallic or black; inserted on the fronto-clipeal suture, 11-segmented, subclavate in females, more or less modified in males: antennomere I swollen or elongate (respectively in the main lineages); II and III cup-like; IV enlarged, anteriorly normal or bilobate; V and VI more or less enlarged; VII enlarged with or without a dorsal spine extension; VIII-X more or less enlarged and variously shaped; XI elongate or subquadrate; last antennomere similarly shaped in both sexes.

Pronotum metallic, green, blue or violet, in one species (D. promelaena) black; usually elongate, with two oblique impressions on the anterior third in males. Mesopleura not or only slightly depressed just behind the anterior margin, not touching each other; mesosternum not differentiated anteriorly; metasternum wide. Elytra metallic, green or blue, flattened, in one species 
evidently sinuate on external side; wings normally developed. Coxae and trochanters yellow, black or metallic (green, blue or violet); femurs ant tibiae yellow or reddish; male fore tibiae in one lineage simple, in the other lineages with a laminar external expansion, more or less extended, or only a short inflated expansion; tarsi not modified, yellow or reddish with dark at apex or almost completely dark.

Abdomen metallic green, blue, violet, or black; posterior margin of male last abdominal sternite emarginated, rounded in females. Male genitalia with lobes of parameres elongate in some species; aedeagus with two distinct hooks, subequal in size and directed backward; endophallus with sclerotised apical portion bidentate, the apical hook smaller, and outwardly directed.

Commented catalogue. For each species the following information is indicated: the synonymies; the type locality and the type material, also for synonyms; a diagnosis and eventually some taxonomic remarks; the distribution, with the list of localities divided, from West to East, by states and districts, and with the acronym of the collection where the material is preserved and/or literature citations.

\section{Group obscuritarsis}

Diaphorocera carinicollis Chobaut, 1921

Diaphorocera carinicollis Chobaut, 1921: 298.

Type locality. "Touggourt” (Chobaut, 1921).

Type material. Male lectotype and five paralectotypes, one male and four females, were examined (MNHN). The lectotype has the following labels: "Touggourt/Mai 1898/ Dr. A. Chobaut" (white, printed); " 0 Diaphorocera/carinicollis/Chobaut" (white, handwritten); LECTOTYPE (red, printed); "Diaphorocera/carinicollis Chobaut, 1921/lectotype/Jan Batelka desig. 2003" (white, printed).

Two paralectotypes have the following labels: "Touggourt/Mai 1898/ Dr. A. Chobaut" (white, printed); ơ (white, handwritten); "carinicollis/Chobaut/types" (white, handwritten);

"MUSÉUM PARIS/1942/Coll. Dr. A. CHOBAUT" (white, printed); "PARALECTOTYPE" (red, printed); "Diaphorocera/ carinicollis Chobaut, 1921/paralectotype/Jan Batelka desig. 2003" (white, printed); "Touggourt/Mai 1898/ Dr. A. Chobaut" (white, printed). "o" (white, handwritten); "MUSÉUM PARIS/1942/Coll. Dr. A. CHOBAUT" (white, printed); "PARALECTOTYPE" (red, printed); "Diaphorocera/carinicollis Chobaut, 1921/paralectotype/Jan Batelka desig. 2003” (White, printed). The last three female paralectotypes have the same labels, as follows: "Touggourt/Mai 1898/ Dr. A. Chobaut" (white, printed); “o" (white, handwritten); "PARALECTOTYPE" (red, printed);
"Diaphorocera/carinicollis Chobaut, 1921/paralectotype/Jan Batelka desig. 2003" (white, printed).

One of the females lacks right middle tarsus.

Diagnosis. Male. (Figs 3a; 4a; 5a; 6a; 7a, h; 8a-c; 12). 13-15 mm length. Body blue-violet metallic, but elytra green metallic, antennomere I dark, II darkling orange and II-XI orange, mandibles black, clypeus and labrum dark or partially reddish, maxillary palpi reddish, frons between antennal sockets black, antero-lateral portion of head, anterior to eyes, dark, femurs and tibiae orange, tarsi dark but tarsomere I of fore and middle tarsi orange and basis of II fore tarsomere reddish. A red frontal spot more or less evident. Long yellow setae on posterior and ventral portions of head, pronotum, scutellum, thoracic pleurites and fore coxae.

Frontal calli small and only weakly developed, anterior portion not modified, scarcely visible on lateral view, posterior margin, on dorsal view reaching about the middle of the inner margin of eye. Temples subparallel, maximum width of head on temples. Labrum about 1,5 times longer than clypeus. Maxillary palpomere III than II, distal end of III obtuse, IV slender and parallel, about 2 times as long as the width. Anterior side of antennomere III with setae longer than those on II; anterior margin of IV not bilobate, only with an elongate protrusion; anterior margin VII without appendix; spine-like setae on anterior apex of antennomeres IV-VII; posterior side of VI-IX only with short setae; antennomere VII only slighly wider than VI and slightly narrower than VIII; XI subquadrate, without chitinous and shiny lines.

Pronotum wide, robust, anteriorly slightly narrowed, maximum width on fore side slightly narrower than temples, fore oblique grooves deep and well developed; middle longitudinal smooth line well evident, forming an apparent carena. External margin of elytra posteriorly greatly sinuate.

Fore tibiae simple, subcylindrical; external spur of hind tibiae widely spatuled.

Parameres in ventral view slender and only slightly angulated at the base of lobes; lobes elongate (ratio lobes length/parameres length: 0.39); aedeagus as in Fig. 8c.

Female. Body green-blue metallic but elytra green-cupreous metallic, antennae, labrum and maxillary palpi dark. Antennomere XI subquadrate.

Taxonomic remarks. This species was recently redescribed by Batelka (2004), who figured the male genitalia and antenna, previously unclearly represented by Chobaut (1921). 


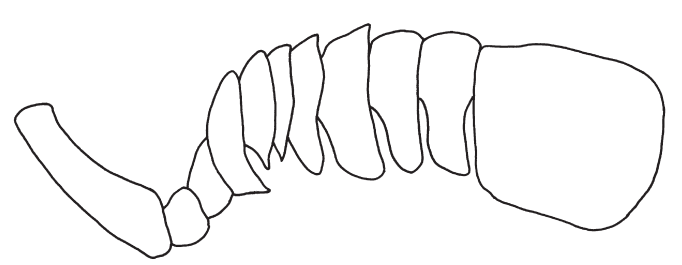

a

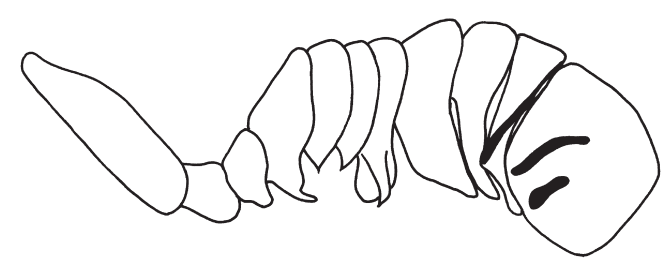

c

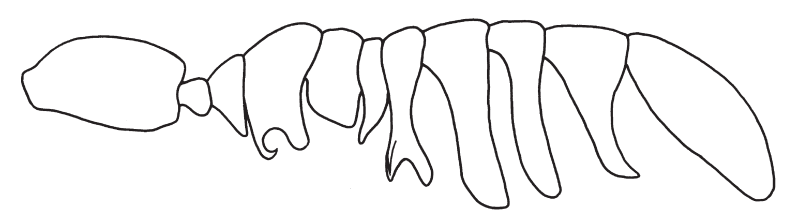

$\mathrm{e}$

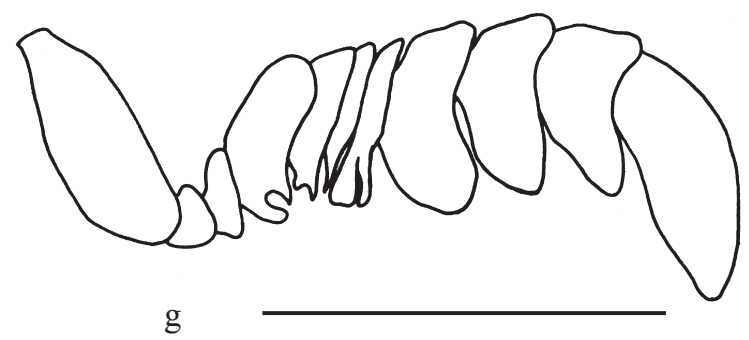

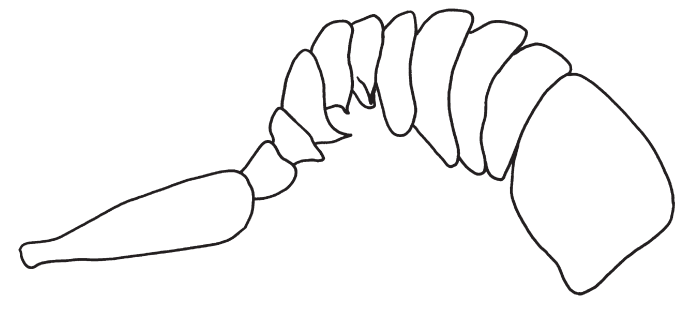

$\mathrm{b}$

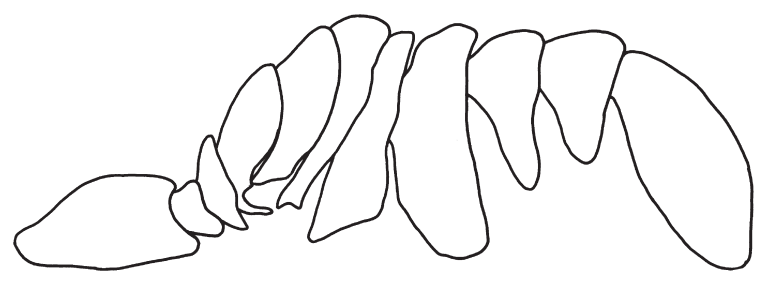

d
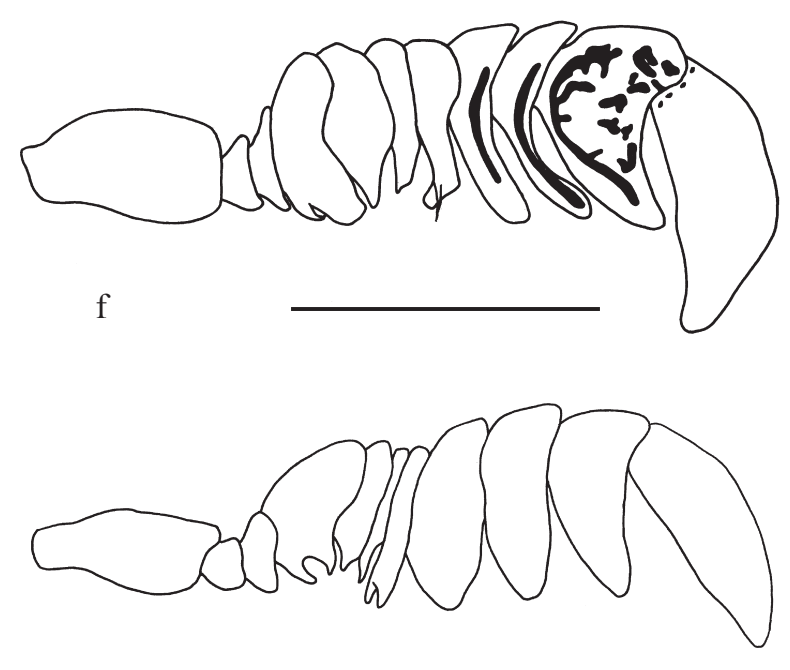

$\mathrm{h}$

Fig. 3. Male left antenna, dorsal view: (a) D. carinicollis, (b) D. johnsoni, (c) D. obscuritarsis, (d) D. promelaena, (e) D. peyerimhoffi, (f) D. sicardi, (g) D. chrysoprasis, (h) D. hemprichi. Scale bars $=1 \mathrm{~mm}$.

Distribution (Fig. 12). Algeria. Algeria (Kaszab, 1951; Dvořak, 1989); Touggourt (Chobaut, 1921; Batelka, 2004; MNHN). Tunisia. $20 \mathrm{Km}$ Tozeur on road NeftaHazoua (CB); S Kebili (Batelka, 2004; CBA).

Diaphorocera johnsoni Kaszab, 1983

Diaphorocera johnsoni Kaszab, 1983: 180.

Type locality. "Saudi Arabia, Eastern Prov., Udhailiyah Camp" (Kaszab, 1983).
Type material. Three examined paratypes (HNHM) have the following labels. One male: "SAUDI ARABIA / Eastern Prov. / D. A. Pitcher" (white, printed); "Mishash Al Udhailiyah / 13/ IV/82 / No 96" (white, handwritten); "Paratypus 1983 ô / Diaphorocera/johnsoni / Kaszab" (white with red frame, handwritten, except "Paratypus" printed with red ink); "Diaphorocera / johnsoni / Kasz. / Dr. Z. Kaszab det., 1983" (white, handwritten, except the underlined part of the last line, printed). One male and one female with the same labels, but "29.IV. / 1982, no. 172" and indications of the sex; this male has an additional white label with the genitalia and the last three abdominal segments glued. 
Diagnosis. Male. (Figs 3b; 4b; 5b; 6b; 7b, i; 8d-f; 11). 10-12 mm length. Head, pronotum and elytra blue-green metallic, thoracic sternites and abdomen blue-violet metallic, frons between antennal sockets metallic, antennomere I, antero-lateral portion of head, anterior to eyes dark, antennomeres II-XI, maxillary palpi, femurs and tibiae orange, labrum, clypeus, antennomere I and last 2-3 tarsomeres dark, anterior margin of labrum yellow, external margin of mandibles reddish. Very long white setae on posterior and ventral portions of head, pronotum, scutellum, thoracic pleurites and fore coxae.

Frontal calli small and only weakly developed, anterior portion not modified, not visible on lateral view, posterior margin, on dorsal view reaching about the middle of the inner margin of eye. Temples parallel, maximum width of head on eyes. Labrum about 1,5 times as long as clypeus. Maxillary palpomere III shorter than II; distal end of III obtuse; IV slender and parallel, about 2 times as long as the width. Anterior side of antennomere III with setae as long as those on II; anterior margin of IV not bilobate, only with a short digitiform protrusion; VI with a dorsal spur; spine-like setae on anterior apex of antennomeres IV-VII, very robust on VII; anterior margin of VII without appendix; posterior side of antennomeres VI-IX only with short setae; VII distinctly wider than VI and slightly narrower than VIII; XI subquadrate, without chitinous and shiny lines, apically slightly pointed.

Pronotum slender, maximum width on fore side distinctly narrower than temples, fore oblique grooves only weakly developed. External margin of elytra posteriorly only slightly sinuate.

Fore tibiae simple, subcylindrical; external spur of hind tibiae widely spatuled.

Parameres in ventral view slender (length/width is almost 1), with elongate lobes (ratio lobes length/parameres length: 0.38); aedeagus as in Fig. 8f.

Female. Colouration as in male but antennae, labrum and maxillary palpi dark; fore margin of labrum light; femurs and tibiae orange-yellow. Temples narrow and parallel, maximum width of head on eyes; antennomere XI subquadrate.

Distribution (Fig. 11). Saudi Arabia. Saudi Arabia (Dvořak, 1989); Eastern Province, Udhailiyah Camp (Kaszab, 1983; HNHM); Mishash, Al Udhailiyah (Kaszab, 1983); Jaww Dukha (Kaszab, 1983); United Arab Emirates. Dubai Emirate, Nahabi (UCD); Abu Dhabi Emirate, Al Aïn, Al Jahar-Al Saad on road Al Aïn-Abu Dhabi (CB).

\section{Diaphorocera obscuritarsis Fairmaire, 1885}

Diaphorocera obscuritarsis Fairmaire, 1885: 38.

Diaphorocera obscuritarsis var. ruficornis Pic, 1923: 10 syn. n.

Type locality. "Biskra" (Fairmaire, 1885). D. obscuritarsis var. ruficornis: "Egypt: Massara” (Pic, 1923)

Type material. Male holotype (MNHN) and twelve paratypes (HNHM) examined. The holotype has the following labels: "Biskra" (white, handwritten); "obscuri / tarsis" (white, handwritten); "Diaphorocera/ obscuritarsis" (white, handwritten). All the paratypes have the same following labels: "Algérie / Biskra / J. Merkl / Mai 1884" (white with thin black frame, printed); "coll. R. Oberthür/ ex coll Deyrolle" (white, printed); "Paratypus 1885 / Diaphorocera / obscuritarsis / Fairmaire" (white with red frame, handwritten, except "Paratypus" printed with red ink). The second paratypes of the line, one female, has additional labels, below the previous three: "Diaphorocera / obscuritarsis" (white, handwritten); "Fairm type" (white, handwritten, upturned).

Four females paratypes lack some body parts: both antennae (except the first two antennomeres, still present); hind right leg (except the coxa, still present); the last two tarsomeres of fore right legs (in two females).

The female syntype of D. obscuritarsis var. ruficornis (MNHN) was examined. According to Pic (1923), the male syntype is preserved in the Alfieri's collection (Cairo, Egypt), but it was not examined. The female has the following labels: "MASSARA / MAI" (white, printed); " 45 " (white, handwritten); "ex Chakour" (white, handwritten); "D. Hemprichi / var" (white, handwritten); "obscuritarsis / var ruficornis / mihi" (white, handwritten); "Museum Paris / Coll. M. Pic" (white, printed).

Some body parts of the female syntype are missing: left antenna, except the first two antennomeres; left fore leg, except coax and trochanter; right hind leg; right elytron.

Diagnosis. Male. (Figs 3c; 4c; 5c; 6c; 7c, 1; 9c; 8g-i; 11). $9-15 \mathrm{~mm}$ length. Violet-blue metallic, rarely greenish, except dark trochanters and tarsi, and orange antennae, clypeus, labrum, maxillary palpi, galae, femurs and tibiae; antennomere I slightly dark in some specimens; fons between antennal sockets black; antero-lateral portion of head, anterior to eyes, dark; a red frontal spot usually present.

Frontal calli not clearly visible on lateral view, posterior margin on dorsal view reaching about the middle of the inner margin of eye, anterior portion not modified. Temples slightly curved, about as wide as eyes. Labrum about 1,5 times as long as clypeus. Maxillary palpomere III shorter than II; distal end of III obtuse; IV short and sub-rectangular, about 1,5 times as long as the width. Anterior side of antennomere III with few 

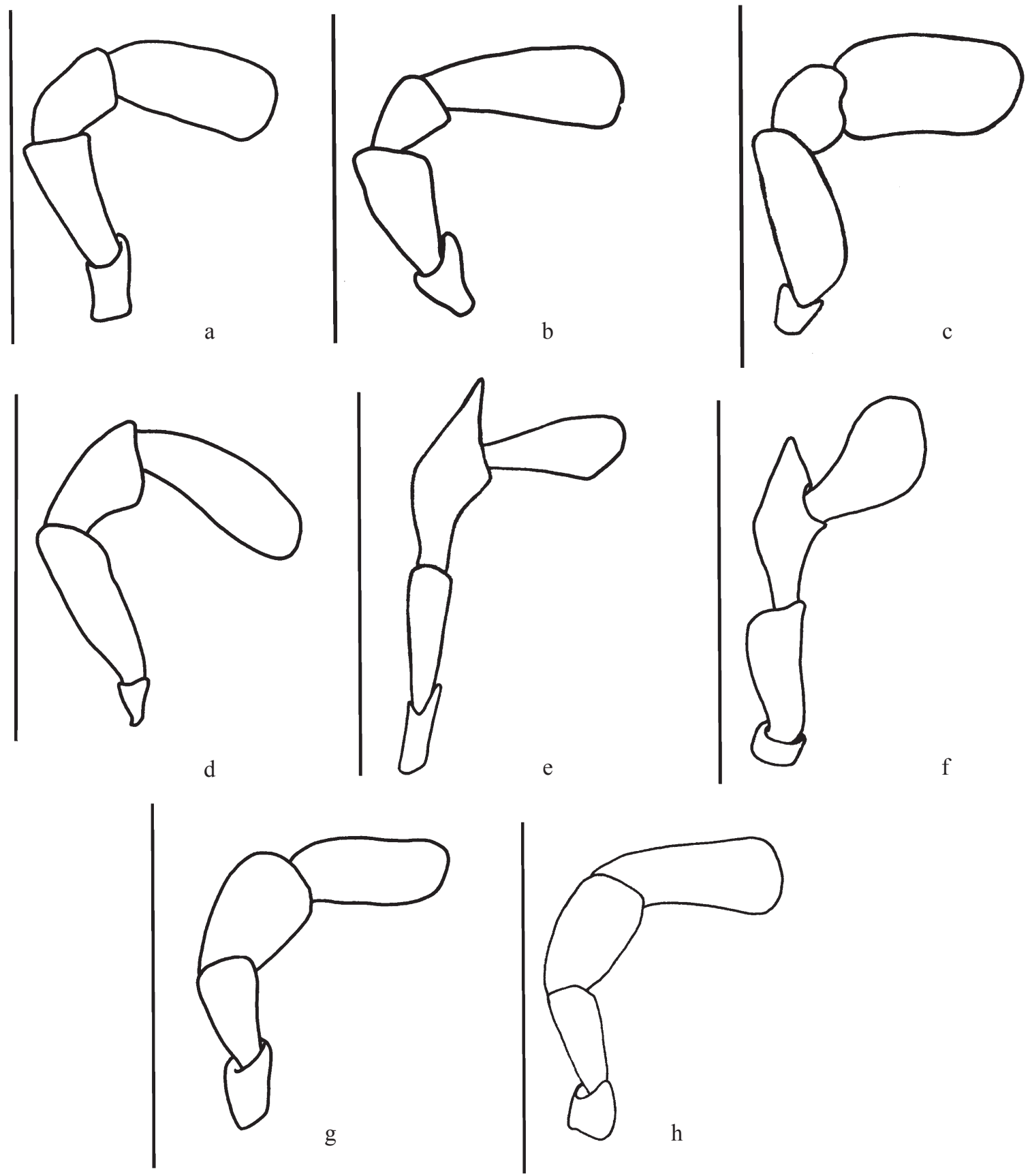

Fig. 4. Male left maxillary palpus, dorsal view: (a) D. carinicollis, (b) D. johnsoni, (c) D. obscuritarsis, (d) D. promelaena, (e) D. peyerimhoffi, (f) D. sicardi, (g) D. chrysoprasis, (h) D. hemprichi. Scale bars $=1 \mathrm{~mm}$.

setae, distinctly shorter than those on II; anterior margin of IV not bilobate, only with a digitiform protrusion; anterior margin of VII with a dorsal slender and pointed appendix; spine-like setae on anterior apex of antennomeres V-VII; posterior side of VI-IX only with short setae; one black, chitinous and shiny line on fore margin of $\mathrm{X}$ and two oblique in the middle of XI; XI subquadrate.

Pronotum anteriorly with two oblique and deep grooves. Fore tibiae simple, subcylindrical; external 
spur of hind tibiae widely spatuled. External margin of elytrae posteriorly only slightly sinuate.

Parameres in ventral view short, abruptly angulated anteriorly, and stout (length/width almost 1), lobes relatively long (ratio lobes length/parameres length: 0,43); aedeagus as in Fig. $8 \mathrm{f}$.

Female. Colouration as in male but antennae, labrum and maxillary palpi dark; fore margin of labrum dark; femurs and tibiae yellow-orange. Temples wide, slightly enlarged, maximum width of head on temples. Antennomere XI subquadrate.

Taxonomic remarks. The variety ruficornis, never collected after the description, represents only a phenotype with the antennomeres completely red.

Distribution (Fig. 4). Mauritania. Ouadane (MNHN); Alzas. Embouchure (MNHN); Ile Tidra (MNHN); Morocco. Sous, Aïn Chaïb (Kocher, 1953; 1956); Arazane, Tifidelt (MNHN); Bou Tlidat (Kocher and Reymond, 1954); Zguilma (ISR; Kocher, 1956); Algeria. Algeria (Kaszab, 1951; Dvořak, 1989); Bou Sàada (MNHN); Hoggar, Tamouda (MNHN; Peyerimhoff, 1931); Biskra (Fairmaire, 1885; Bedel, 1895; CP; HNHM; MNHN); Ed Dor (HNHM); Haut Igharghar, Oued Tinbart (MNHN; Peyerimhoff, 1931); Haut Igharghar (MNHN); Amguid (MNHN; Peyerimhoff, 1931); Tifedest, Aguelmame Araren (Peyerimhoff, 1931); Tunisia. Tunisia (Kaszab, 1951; Dvořak, 1989); Tozeur, road Nefta-Hazoua Km 20 (CB); Khanget Oum-Ali (Bedel, 1895); Egypt. Egypt (Pic, 1923; Cros, 1939; Kasazb, 1951; Dvořak, 1989); Arabian desert, wadi E Maadi (Alfieri, 1976); Arabian desert, wadi W Kosseir (Alfieri, 1976); Arabian desert, wadi Beida (Alfieri, 1976); Sinai (Chikatunov, 1999); Israel-Palestine. Dead Sea (Chikatunov, 1999); Northern Negev (Chikatunov, 1999); Southern Negev (Chikatunov, 1999); Arava Valley (Chikatunov, 1999).

\section{Group hemprichi}

Diaphorocera chrysoprasis Fairmaire, 1863

Diaphorocera chrysoprasis Fairmaire, 1863: 644.

Diaphorocera kerimii Fairmaire, 1875: 530.

Type locality. "Biskra" (Fairmaire, 1863).

D. kerimii: "Gafsa" (Fairmaire, 1875)

Type material. Fairmaire (1863) did not indicate where the female holotype is preserved, and we did not find it in the collections we examined.
The female holotype of D. kerimii (MCSN) was examined. It has the following labels: "Tunisia / Gafsa Aprile / Abdul Kerim 1873" (white printed, except "Gafsa Aprile", handwritten); "4" (white, handwritten); "Diaphorocera / kerimii / Fairm" (white, handwritten); "Typus" (white, printed with red ink); "Museo Civico / di Genova" (white, printed). The holotype is in good conditions even though both antennae are glued on the same label of the specimen, except the first two antennomeres which are still on head.

Diagnosis. Male. (Figs 6g; 7g; 8g; 9g; 10f, o; 11g, h, i). 6-10 mm length. Green metallic, sometimes with golden reflection on head and prothorax, rarely elytra green-blue; antennae, mouthparts (except the external side of mandibles), frons between antennal sockets, antero-lateral portion of head, anterior to eyes, and legs (except coxae) orange.

Frontal calli with posterior margin on dorsal view, reaching the posterior half of the margin of eye, slightly visible on lateral view; anterior portion evidently arcuate but not prolonged in the middle, externally not differentiated. Temples very elongate and parallel, slightly shorter than the longitudinal diameter of eye, the maximum width of head on eyes. Labrum about 2 times as long as clypeus. Maxillary palpomere III subequal to II; distal end of III obtuse; IV longer than twice its maximum width. Anterior side of antennomere III with few setae, about as long as those on II; anterior margin of IV, V and VII bilobate; posterior side of antennomeres III-VIII with short setae; VIII-X largely transverse and flattened, VIII distinctly wider than the others, apically rounded, IX apically truncate, X halfmoon like; width of X distinctly shorter than the length of XI; XI elongate.

Pronotum narrow and elongate, anteriorly with two oblique and deep grooves. Fore tibiae dorsally flattened with a laminar expansion on the external side upward curved; external spur of hind tibiae narrowly spatuled. External margin of elytra posteriorly not evidently sinuate.

Lobes of parameres relatively short (ratio lobes length/parameres length: 0,28); aedeagus apically stout, with sligthly elongate hooks.

Female. Colouration as in male, except mouthparts slightly darker; frons between antennal sockets and clypeus basally metallic. Temples elongate and parallel; maximum width of head on eyes. Antennomere XI elongate.

Taxonomic remarks. D. kerimii was synonymised with D. chrysoprasis by Bedel (1895). After the examination 


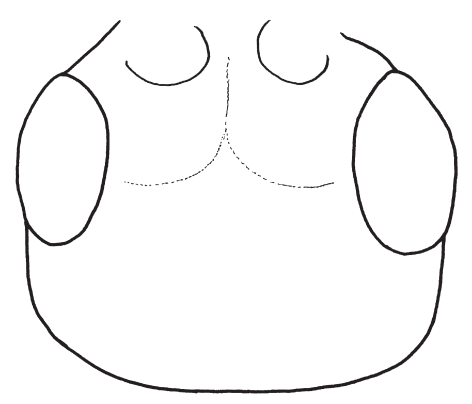

a

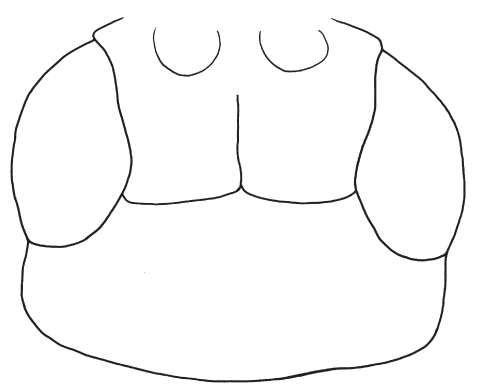

d

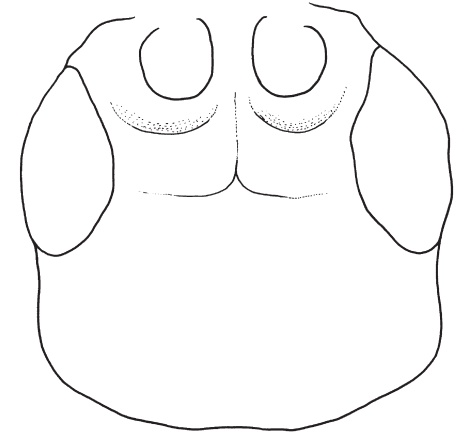

b

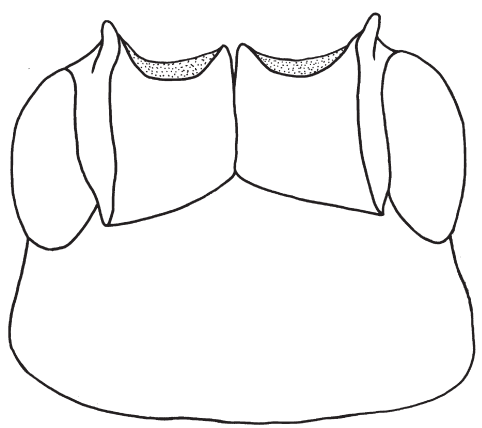

e

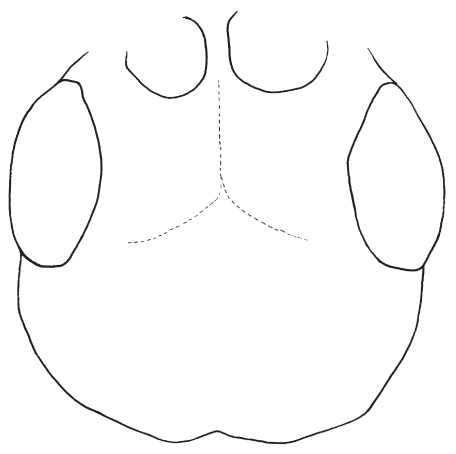

c

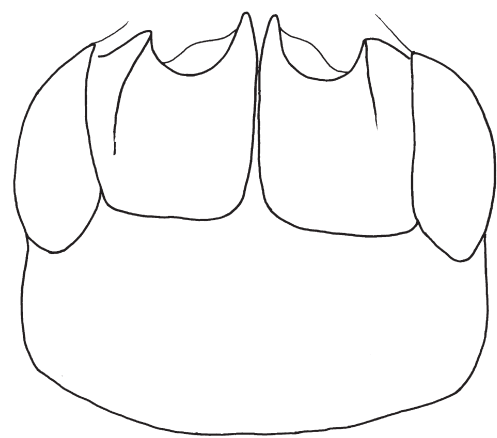

f

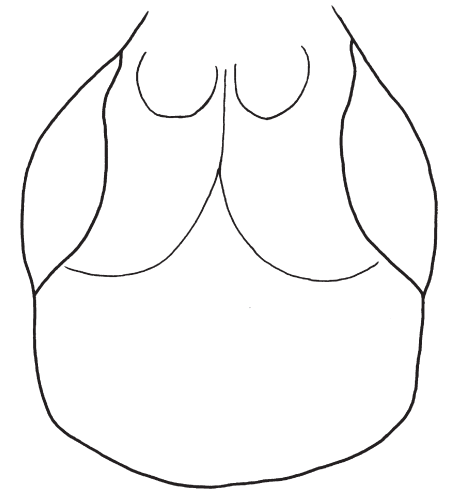

g

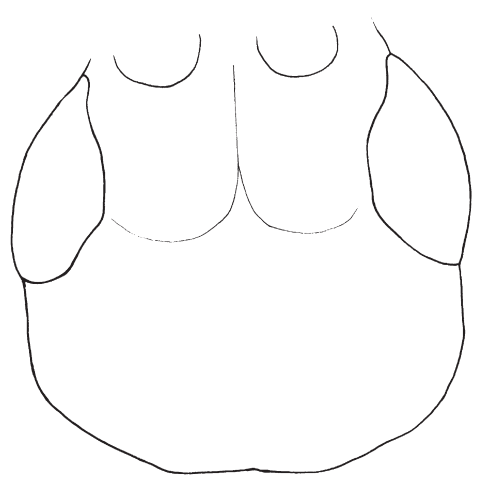

$\mathrm{h}$

Fig. 5. Male head, dorsal view: (a) D. carinicollis, (b) D. johnsoni, (c) D. obscuritarsis, (d) D. promelaena, (e) D. peyerimhoffi, (f) D. sicardi, (g) D. chrysoprasis, (h) D. hemprichi. Scale bars $=1 \mathrm{~mm}$.

of the holotype of the former taxon we confirmed this synonymy with some doubts. In fact this specimen is a female lacking both antennae; the general shape and several features agree with chrysoprasis, except the larger size, and the pronotum wider and with sides not converging basally. Several specimens from Gafsa - the type locality of $D$. kerimii - and adjacent zones were examined, all referable to typical $D$. chrysoprasis.

Some morphological differences with $D$. hemprichi are discussed below. 
Distribution (Fig. 3). Mauritania. Khatt Atoui, Tamarat (MNHN); Algeria. Algeria (Kaszab, 1951; Dvořak, 1989); Bou Sàada (Pic, 1897; MNHN; HNHM); Oued Chaïr (HNHM); Biskra (Fairmaire, 1863; HNHM; MNHN); Laghouat (HNHM); Touggourt (MNHN; HNHM); Aïn Sefra (HNHM; MNHN); Ghardaïa (MNHN); Amguid, Tassili ouest (MNHN); Timuit (CB); Tunisia. Tunisia (Kaszab, 1951; Dvořak, 1989); S Kebili, Al Blidet (CBA); Od. Fekka (MHNG); Maknassy (Normand, 1949); Gafsa (Fairmaire, 1875; MCSN); Tozeur (Normand, 1949; MNHN); Tozeur, 10 Km SW Tozeur on road P3 (CB); Tozeur, $25 \mathrm{Km}$ from Tozeur on road P3 (CB); Nefta (CBA); El Golaa (Zaafrane) (CS); $7 \mathrm{Km}$ N Douz on road C206 (CB); Zarzis (MHNG; MNHN; HNHM); 30 Km W Nefta, Hazoua (CBA); Libya. Tripolitania, Al Aziziyah (CB; CR); Tripolitania, Suq Ai Vchamis (CK).

\section{Diaphorocera hemprichi Heyden, 1863}

D. hemprichi hemprichi Heyden, 1863: 127.

Type locality. D. hemprichi hemprichi: "Aegypten" (Heyden, 1863).

Type material. Types of the nominate subspecies were not examined; they are probably preserved at the Zoological Museum of Berlin.

Diagnosis. Male. (Figs 3h; 4h 5h; 6h; 7g, d; 8h; 9l-n; 11n). 6-12 mm length. Similar to D. chrysoprasis except for the following characters: temples shorter and slightly curved; antennomere VIII slightly wider than IX and X; anterior portion of antennomeres VIII-IX apically narrowing; width of X slightly shorter than the length of XI. Pronotum slightly wider than in male; foretibiae with a laminar expansion also on the internal side. Lobes of parameres raised at base and more diverging externally.

Female. Colouration as in male, except mouthparts slightly darker and clypeus basally metallic. Temples progressively converging posteriad; maximum width of head on eyes. Antennomere XI elongate. Pronotum slightly wider.

\section{D. hemprichi saudita Kaszab, 1983: 179.}

Type locality. D. hemprichi saudita: "Saudi Arabia, Eastern Prov., Udhailiyah Camp” (Kaszab, 1983).
Type material. Four paratypes of D. hemprichi saudita (HNHM) were examined. One male and one female have the same following labels: "Jaww Dukha / 7.V.1982 / no. 186" (white, printed); "SAUDI ARABIA / Eastern Prov. / D. A. Pitcher" (white, printed); "Paratypus 1983 [ $\hat{0}$ and 9 respectively]/ Diaphorocera / hemprichi ssp. / saudita / Kaszab" (white with red frame, handwritten, except "Paratypus" printed with red ink); "Diaphorocera / hemprichi ssp. / saudita Kaszab / Dr. Z. Kaszab det., 1983" (white, handwritten, except the underlined part of the last line, printed); on an additional label hare glued the tegmen and penis, the last abdominal segment and the speculum gastrale. One third male has the same labels, but "28.VI.1982 / no. 192". The fourth male paratype has the following labels: "Udhailiyah Camp / 29.IV.1982 / no. 171" (white, printed); "SAUDI ARABIA / Eastern Prov. / D. A. Pitcher" (white, printed); "Paratypus 1983 ô / Diaphorocera / hemprichi ssp. / saudita / Kaszab" (white with red frame, handwritten, except "Paratypus" printed with red ink).

Diagnosis. Very similar to the nominate subspecies, being the differences, summarised by Kaszab (1983), very weak: (a) the head has a sparse puncturation in the nominate subspecies, but is almost smooth in D. hemprichi saudita; (b) the pronotum is shorter and broader in the former and more elongate and narrow in the latter, moreover the female pronotum of the Arabian race has punctures very sparse, uniform and fine.

Taxonomic remarks. D. hemprichi and D. chrysoprasis are very close and difficult to distinguish, except for the antennal and head features listed in the diagnostic key. Kaszab (1951) emphasised the difference between these species as concerns the inner side of male fore tibia. That of $D$. hemprichi is expanded to form a lamina (Figs $10 \mathrm{~g}, \mathrm{p}$ ), but in the second species the inner margin is simple. Actually, in the Ain-Séfra (Algerian Sahara) population, living in syntopy with $D$. chrysoprasis, we found a great variability of this character, and some individuals have the inner side scarcely or not expanded.

Distribution (Fig. 11). D. hemprichi hemprichi. Morocco. Draa Region, El Kantara (Pardo Alcaide, 1961); Seguia el Hamra, Hauga Ramala (Pardo Alcaide, 1961); Oued Hasi Belibilia (ISR); Bou-Denib (Kocher, 1956); Draa Valley, Agdz (CB); Gara Sbaa, Gara Bou Tlidat (ISR); Zguilma (Kocher, 1956); Rio de Oro, Smamit, Uad Komba (Pardo Alcaide, 1961); Algeria. Bou Sàada (MNHN); Oued Chaï (HNHM); Les Terres Blanches (CP); Aïn Sefra (ISR; MNHN); Ghardaïa (MNHN); Amguid (Peyerimhoff, 1931); Tunisia. Gabes (MVE); Egypt. Egypt (Heyden, 1863; Cros, 1939; Kaszab, 1951; HNHM); Libyan desert, Abu Rauwash (Alfieri, 1976); 
Libyan desert, Kirdasah (Alfieri, 1976; CB); Saqqarah (Pic, 1900); Masarah (MVE); Cairo, Mena, Hotel Garden (OUM); Arabian desert, wadi SE Cairo (Alfieri, 1976); Israel-Palestine. Jordan Valley (Chikatunov, 1999); Southern Coastal Plain (Chikatunov, 1999); Judean Desert (Chikatunov, 1999); Northern Negev (Chikatunov, 1999); Gevulot (Kaszab, 1957); Urim (Kaszab, 1957).

D. hemprichi saudita. Iran. Abbassi, Bandar Abbas (Dvořak, 1996); 16 Km E Bandar Abbas (HNHM); Saudi Arabia. Saudi Arabia (Dvořak, 1989); Hofuf(Schneider, 1991); Eastern Province, Udhailiyah Camp (Kaszab, 1983); Jaww Dukha (Kaszab, 1983); Dibba (MNHN); Oman. Ras Dhabdhub (Schneider, 1991); United Arab Emirates. Al Jazirat Al Hamra Emirate, crossroad to Airport on road E11 (CB); Ras Al Khaimah Emirate, $23 \mathrm{Km}$ from Airport croosroad on road E18 (Habab-Manama) (CB); Al Aïn, Al Jahar-Al Saad on road Al Aïn-Abu Dhabi (CB); Abu Dhabi Emirate, Al Aïn, Bateen Dunes (CB; CK); Abu Dhabi Emirate, Al Aïn, 3-4 Km E Al Selimat, on road Al Aïn-Abu Dhabi (CB).

\section{Diaphorocera promelaena Fairmaire, 1876}

Diaphorocera promelaena Fairmaire, 1876: 49.

Type locality. "Entre Bou-Sàada et Biskra" (Fairmaire, 1876).

Type material. Two males and seven females paratypes (HNHM) were examined. All the paratypes have the same following labels: "Biskra / R. Oberthür / 1875" (white with thin black frame, printed); "coll. R. Oberthür / ex coll. Deyrolle" (white, printed); "Paratypus 1876 / Diaphorocera / promelaena / Fairmaire" (white with red frame, handwritten, except "Paratypus" printed with red ink). The holotype was not found. Three females lack some parts of the body: the last two tarsomeres of hind left leg and the whole tarsus of hind right leg; the whole tarsus of hind left leg; the whole tarsus of hind right leg and tibia and tarsus of hind left leg.

Diagnosis. Male. (Figs 3d; 4d; 5d; 6d; 7dm; 9a-c; 12c). 6-10 mm length. Head, including the base of clypeus and mandibles, the remaining mouthparts black or dark, pronotum, abdomen, thoracic sternites, coxae, trochanters and antennomere I subopaque black; the rest of the body blue-green metallic with antennomere II-XI, femurs, tibiae and tarsi (or partially dark) orange. Body with white setation, particularly long on templa, pronotum and venter.
Head evidently transverse. Frontal calli bulged, evidently visible on lateral view, posterior margin, on dorsal view, reaching the posterior half of the margin of eye; anterior portion arcuate but not prolonged in the middle, externally not differentiated. Temples parallel and about as long as $2 / 3$ of longitudinal diameter of eye; maximum width of head on eyes. Labrum about 1,5 times as long as than clypeus. Maxillary palpi III shorter than II, distal end obtuse; IV longer than twice its maximum width; anterior side of III with few setae, shorter than those on II. Anterior margin of antennomeres IV, V and VII not bilobate; posterior side of III-VIII with withish setae, particularly long on VI-VII; VII-IX very transverse variously shaped, X triangular, shorter than IX; XI elongate, about as long as 2 times the width of $\mathrm{X}$.

Pronotum wide with fore half greatly curved, anteriorly with two oblique and deep grooves. Fore tibiae modified, with a laminar external expansion only on its distal half; external spur of hind tibiae narrowly spatuled; claws short and curved. External margin of elytra posteriorly slightly sinuate.

Lobes of parameres elongate (ratio lobes length/ parameres length: 0,38); phallobase posteriorly abruptly narrowed; aedeagus short and oblique at apex, hooks very short and differently sized; hooks parallel and oblique.

Female. Colouration and head size as in male. Antennomere XI elongate.

Distribution (Fig. 12). Morocco. Morocco (Dvořak, 1989); Moyenne Moulouya, Tamdafelt (Kocher, 1954; 1956; ISR); Moyenne Moulouya, Ouizret (Kocher, 1954; 1956; ISR); Moyenne Moulouya, Amersid (Kocher, 1954; 1956; ISR); Oued Guir (MNHN); Taourirt (MNHN); Algeria. Algeria (Kaszab, 1951; Dvořak, 1989); Bou Sàada (Bedel, 1895); between Bou Sàada and Biskra (Fairmaire, 1876); Biskra (Bedel, 1895; Baudi di Selve, 1878; CP; HNHM; MNHN); Laghouat (MNHN); Aïn Sefra (MNHN); Ghardaïa (MNHN); Colomb-Béchar (MNHN); Tunisia. Tunisia (Kaszab, 1951; Dvořak, 1989); El Kef (Normand, 1938); Maknassy (Normand, 1949); Tamerza (CBA); Metlaoui (CB); Gabès (Normand, 1949; MHNG; MNHN; MVE); Zarzis (MNHN); Oglet El-Rechid (El Borma) (Bedel, 1895); Egypt. Sinai, Wadi Isla (Alfieri, 1976); Sinai (Chikatunov, 1999). The Alfieri's record, probably re-cited by Chikatunov (1999), need confirmation. 


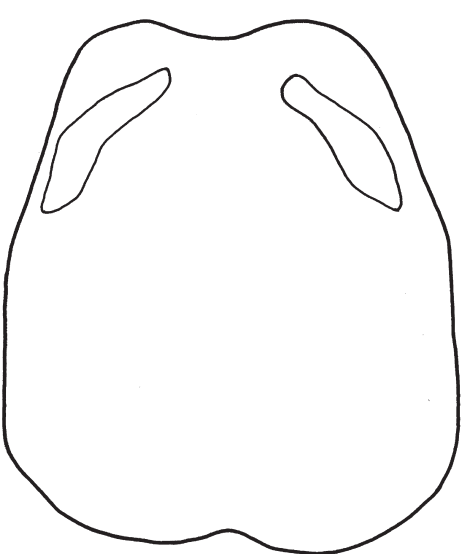

$\mathrm{a}$

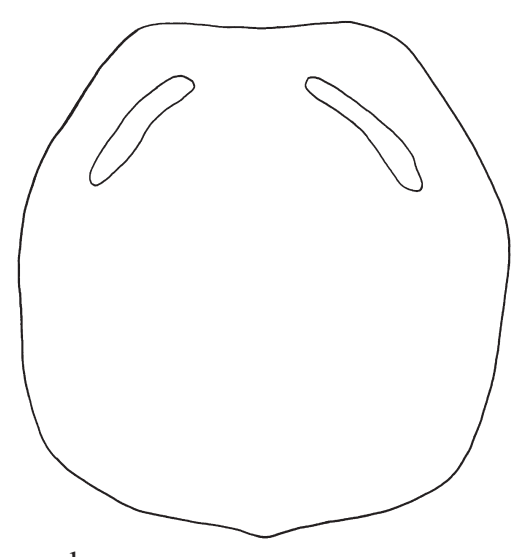

d

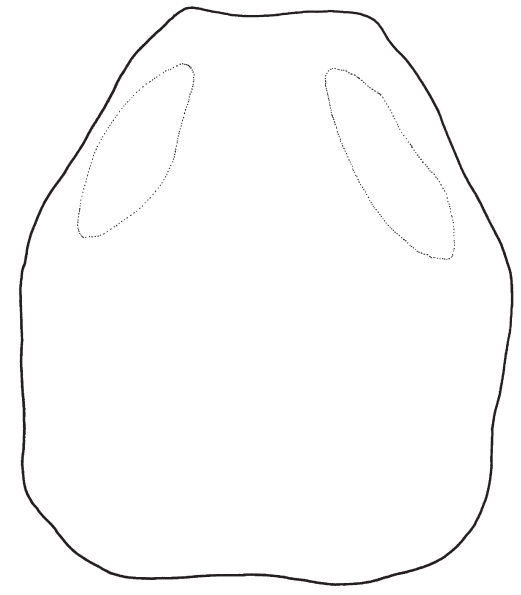

$\mathrm{b}$

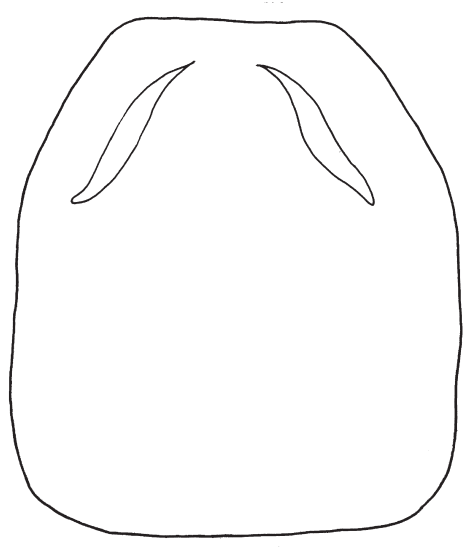

e

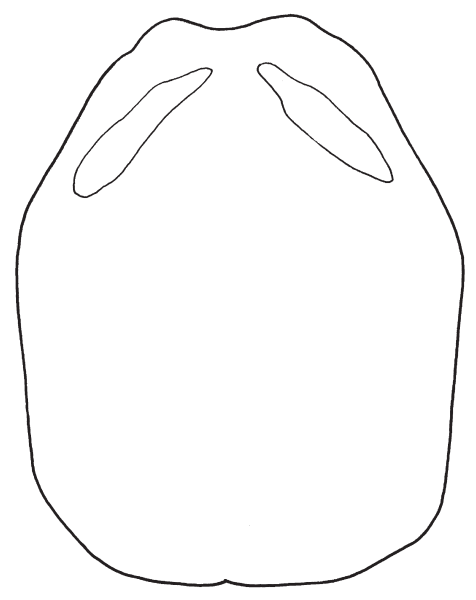

c

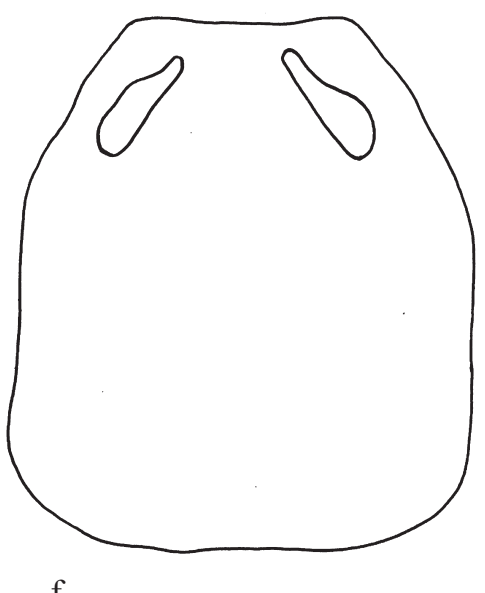

f

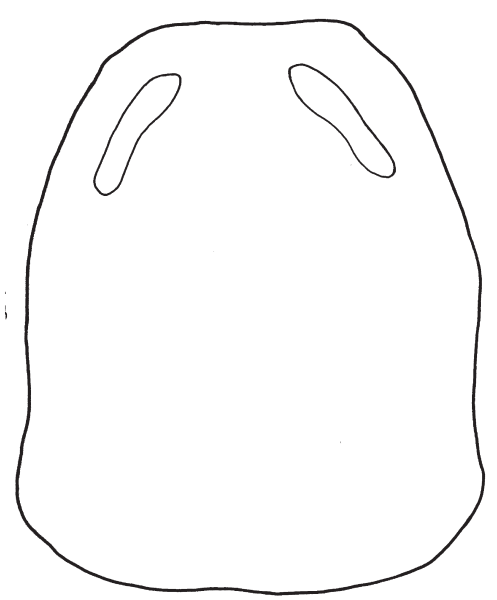

$\mathrm{g}$

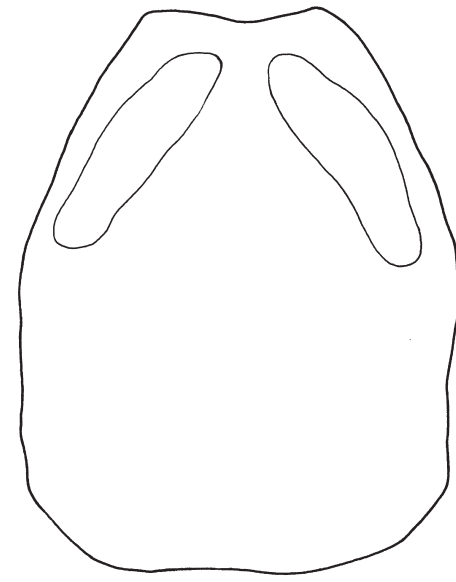

$\mathrm{h}$

Fig. 6. Male pronotum, dorsal view: (a) D. carinicollis, (b) D. johnsoni, (c) D. obscuritarsis, (d) D. promelaena, (e) D. peyerimhoffi, (f) D. sicardi, (g) D. chrysoprasis, (h) D. hemprichi. Scale bars $=1 \mathrm{~mm}$. 
Diaphorocera sicardi Bedel, 1917

Diaphorocera sicardi Bedel, 1917: 364.

Type locality. "Maroc oriental: Fritissa” (Bedel, 1917).

Type material. The male holotype (MNHN), which was examined, has the following labels: "Fritissa/Maroc" (white, handwritten); "type" (white, printed); "Diaphorocera / sicardi / Bedel / n.sp." (white, handwritten); "MUSÉUM PARIS/1930/coll. Sicard" (white, printed).

The holotype lacks the right middle leg, except the coax, still present.

Diagnosis. Male. (Figs 3f; 4f; 5f; 6f; 7e, n; 9d-f; 10). 9-15 mm length. Blue-green metallic with head, thorax and abdomen darker, mandibles and frons between antennal sockets dark; clypeus, labrum, antero-lateral portion of head anterior to eyes, antennae and legs (except coxae and trochanters black and tarsi dark, posterior tibiae sometimes dark) orange; the extension of black colouration on middle and hind legs varies in some specimens, in which is extended on tarsi and most part of tibiae. Labrum with abundant and long yellowish setae.

Head transverse, with a slight depression posterior to calli and on temples, consequently vertex appears slightly bulged. Frontal calli clearly visible on lateral view; posterior margin on dorsal view reaching the posterior half of the margin of eye; anterior portion evidently arcuate and prolonged in the middle with two distinct pointed protrusions, externally differentiated with two elevated keels, apically pointed and anteriorly protruding; apexes of frontal keels slightly inwardly directed (Fig. 8f). Temples slightly enlarged, about as wide as eyes. Labrum about 1,5 times as long as clypeus, with an longitudinal laminar appendix, forming an arch, extended from the apex posteriad. Maxillary palpomere III subequal to II; distal end of III externally elongate and pointed; IV about twice as long as its maximum width and swollen after the middle. Antennomeres IV-X transverse; anterior portion of IV bilobate, basal lobe pointed and curved; anterior portion of VII with a long dorsal spine-like protrusion; VIII-IX with a fore chitinous line, $\mathrm{X}$ with a reticulation of chitinous lines and spots, XI with single chitinous spots at the base; VIII subfalcate, IX falcate, X widely subtrapezoidal, XI very transverse.

Pronotum elongate, subparallel sided, anteriorly slightly angulated with two oblique and deep grooves. Fore tibiae on lateral view with an external short inflated expansion, with a corresponding internal depres- sion, on lateral view gibbose at base; external spur of hind tibiae narrowly spatuled. External margin of elytra posteriorly not evidently sinuate.

Lobes of parameres relatively short (ratio lobes length/parameres length: 0,28 ); aedeagus apically stout, with sligthly elongate hooks.

Female. Colouration as in male, except mouthparts slightly darker; frons between antennal sockets and based of clypeus metallic. Temples elongate and parallel; maximum width of head on eyes. Antennomere XI elongate.

Taxonomic remarks. One female, identified by Kaszab (HNHM), from Tozena, an undetected località, probably of Algeria, differs because of the head and pronotum shiny black, sides of pronotum parallel, antennae and fore tibiae dark.

Distribution (Fig. 10). Morocco. Morocco (Kaszab, 1951; Dvořak, 1989); Guercif (MNHN); Fekkous (Kocher, 1954; 1956; ISR); Fritissa (Bedel, 1917; Kocher, 1956); Algeria. Oum Ali (HNHM); Tunisia. Gafsa (MHNG); Libya. Tripolitania, Tasvadi-Mesari, Bin Ghashir (CK).

Diaphorocera peyerimhoffi Kocher, 1954

Diaphorocera peyerimhoffi Kocher, 1954: 284.

Type locality. "Ouizret” (Kocher, 1954).

Type material. Two males (Type and Cotype) and one female (Allotype) were examined (ISR); they have not an identification label on the pin, which was in the box, just close to the specimens. The type has the following label: "Ouizret/ Moy. Moulouya / (Kocher) 5.53" (white, handwritten, except "Moy. Moulouya" printed); " $\widehat{\widehat{O}}$ " (white, printed); "TYPE" (red, handwritten). The cotype has the following label: "Ouizret / (Moy. Moulouya) / Kocher 5/53" (white, handwritten, except "(Moy. Moulouya)", "Kocher" and "53" printed); "COTYPE" (red, handwritten). The allotype has the following label: "Ouizret / (Moy. Moulouya) / Kocher 5/53" (white, handwritten, except "(Moy. Moulouya)", "Kocher" and "53" printed); "o?" (white, printed); "ALLOTYPE" (red, handwritten).

All the specimens were in good conditions.

Diagnosis. Male. (Figs 3e; 4e; 5e; 6e; 10). 13-17 mm length. Similar to $D$. sicardi except for the following characters: body larger in size; temples evidently wider and enlarged; frontal calli with anterior portion evidently arcuate but not greatly prolonged in the mid- 


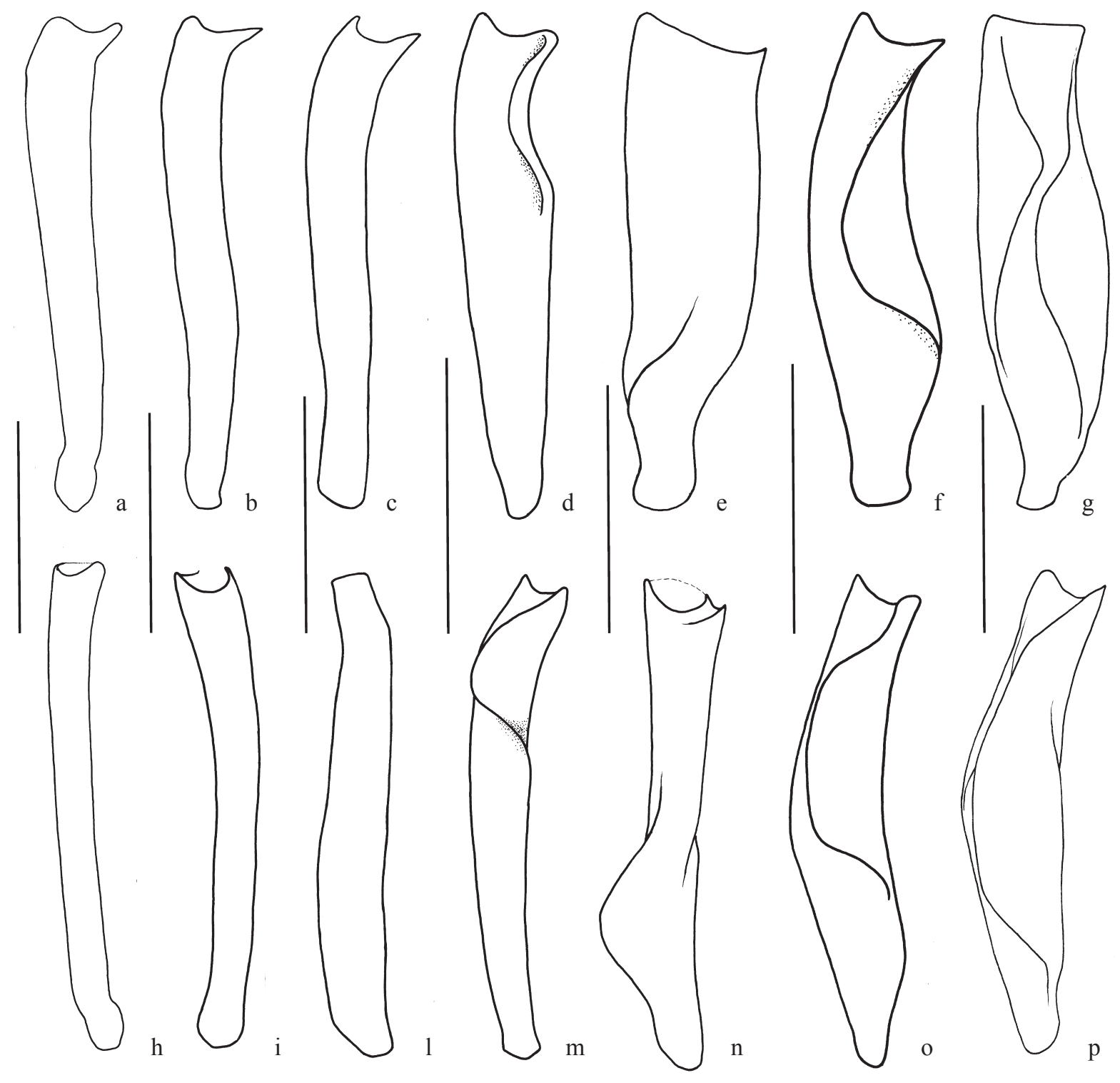

Fig. 7. Male right fore tibia, dorsal view: (a) D. carinicollis, (b) D. johnsoni, (c) D. obscuritarsis, (d) D. promelaena, (e) D. sicardi, (f) D. chrysoprasis, (g) D. hemprichi; lateral view: (h) D. carinicollis, (i) D. johnsoni, (1) D. obscuritarsis, (m) D. promelaena, (n) D. sicardi, (o) D. chrysoprasis, (p) D. hemprichi. Scale bars $=1 \mathrm{~mm}$.

dle, with externally protrusion externally directed (Fig. 8e); apex of maxillary palpomere III more pointed and IV lesser swollen; antennomere IV width basal lobe uncinate, VII bilobed, VIII-IX not falcate, X narrow and subfalcate, chitinous areas absent.

Female. Similar to D. sicardi, but body larger in size; frons with a red spot.
Taxonomic remarks. Diagnostic characters, additional to the Kocher's description (1954), were detected; they permit to clarify the phylogenetic position of this species and to discriminate it from $D$. sicardi. In addition to the features used in the key to the species, the following characters could be evidenced.

Both species have the synapomorphic condition of frontal calli with a raised external keel. In D. peyerim- 

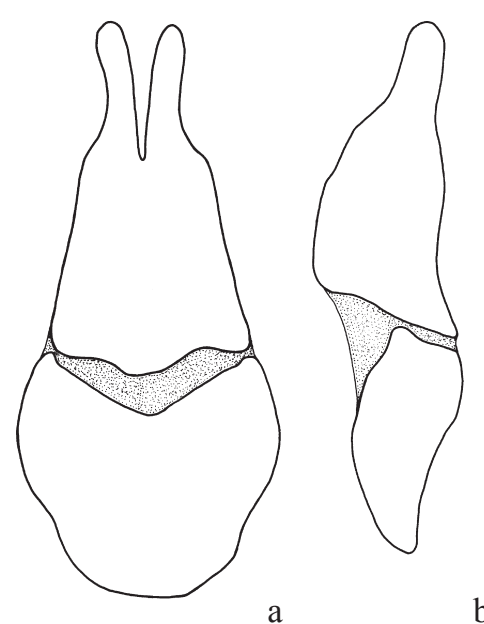

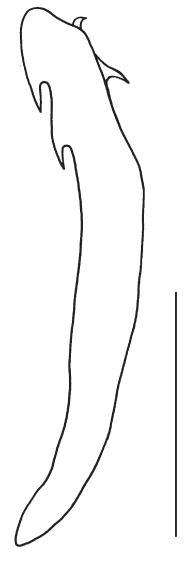

b

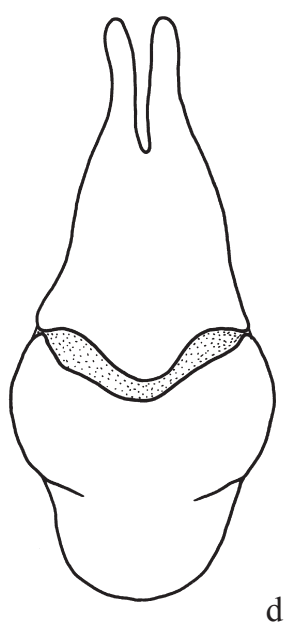

d
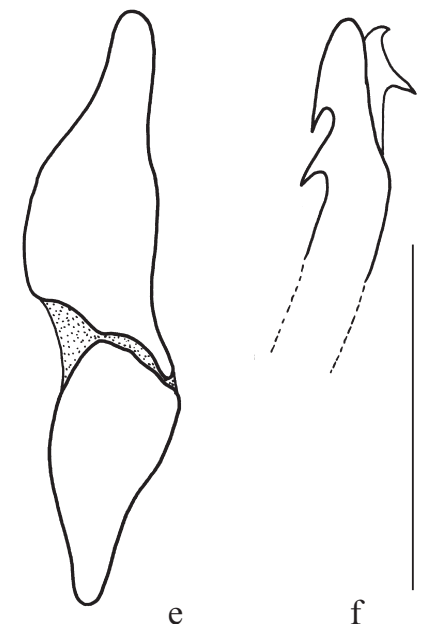

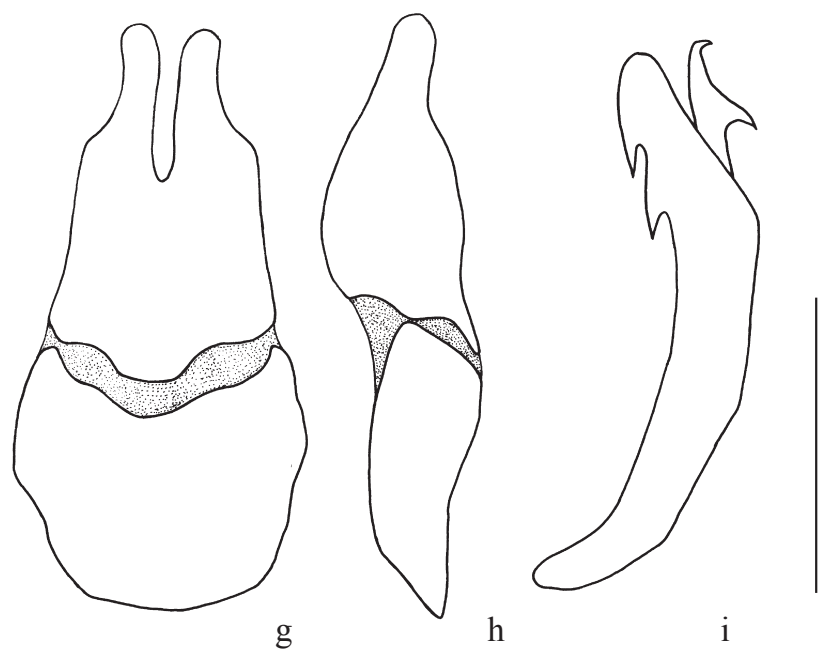

Fig. 8. Male genitalia: D. carinicollis (a) tegmen, ventral view, (b) lateral view, (c) aedeagus, lateral view; D. johnsoni (d) tegmen, ventral view, (e) lateral view, (f) aedeagus, lateral view; D. obscuritarsis (g) tegmen, ventral view, (h) lateral view, (i) aedeagus, lateral view. Scale bars $=1 \mathrm{~mm}$.

hoffi the fore margin of frontal callus is internally prolonged with a low and short protrusion, and externally by the apex of a raised keel outwardly bent (Fig. $8 \mathrm{e}$ ); on the contrary, in D. sicardi the internal protrusion is more extended and the apex of the external keel is forwardly direct (Fig. 8f). The anterior margin of antennomere $\mathrm{V}$ is truncate, while in $D$. sicardi is pointed. Temples of $D$. peyerimhoffi are enlarged posteriad and slightly wider than the width of head on eye, while in D. sicardi are parallel and about as wide as the width of head on eye.
Distribution (Fig. 10). Morocco. Tahiant (Kocher, 1956; MNHN); n' Thala, Tizi Talzent (ISR); Ouizret (Kocher, 1954; 1956); Haut Ziz, Rich (Kocher, 1956; ISR); Mzizel (ISR); Haut Ziz, n’Zala (Kocher, 1956; ISR).

\section{Biogeography}

The entire tribe Cerocomini is primarily a South Palaearctic group, with an extension in East Africa of a new genus related to Diaphorocera (Turco and Bologna, 

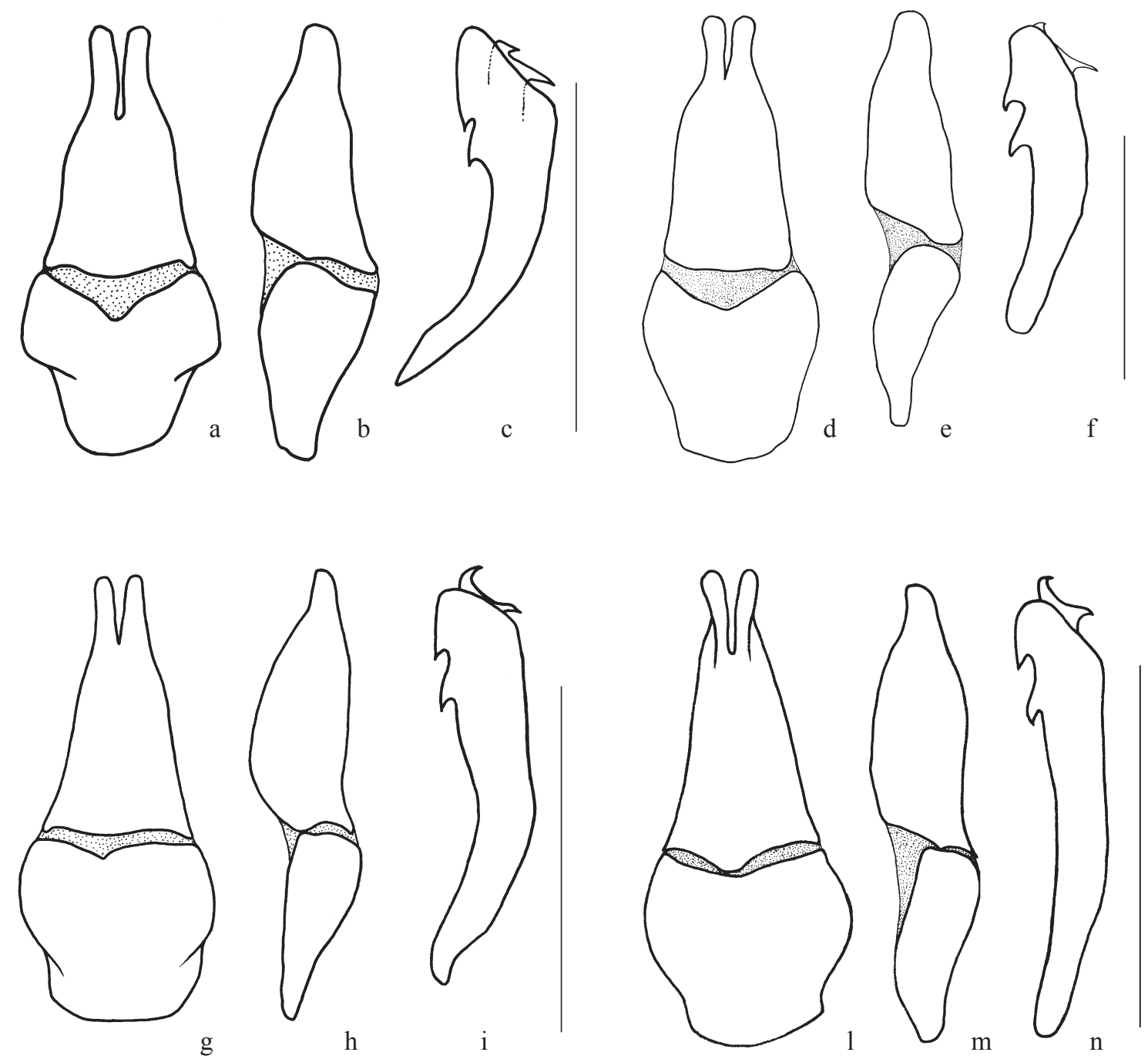

Fig. 9. Male genitalia: D. promelaena (a) tegmen, ventral view, (b) lateral view, (c) aedeagus, lateral view; $D$. sicardi (d) tegmen, ventral view, (e) lateral view, (f) aedeagus, lateral view; D. chrysoprasis (g) tegmen, ventral view, (h) lateral view, (i) aedeagus, lateral view; $D$. hemprichi (1) tegmen, ventral view, (m) lateral view, (n) aedeagus, lateral view. Scale bars $=1 \mathrm{~mm}$.

unpublished). The most genera are West Palaearctic, and only one species of Cerocoma, C. schreberi Fabricius, 1781 is widely distributed from the Iberian Peninsula to W China. Rhampholyssa is distributed in the steppe and deserts of the Don and Turan lowlands, Rhampholyssodes is endemic to the Arabian deserts, Anisarthrocera, in the present meaning (see "Classification") includes one Iraqi-Iranian species, and two East African species belong to the new undescribed genus.

Diaphorocera, is an eremic element, widely distributed from the Atlantic coasts of Western Sahara and
Mauritania, through the entire Sahara and the Arabian peninsula, to the southern Palestinian area and to the dry regions of South Iran. In synthesis it is a typical Saharo-Sindian element (sensu Vigna Taglianti et al., 2000). Its possible relationships with an east African genus (Turco and Bologna, unpublished), one species of which ("Anisarthrocera" semirufa (Fairmaire, 1882) is specialised to semi-desert habitat, suggest interesting hypotheses of a common eremic ancestor of these two genera, split in the Sahara and East Africa, probably during the a more humid Pliocenic phase. 


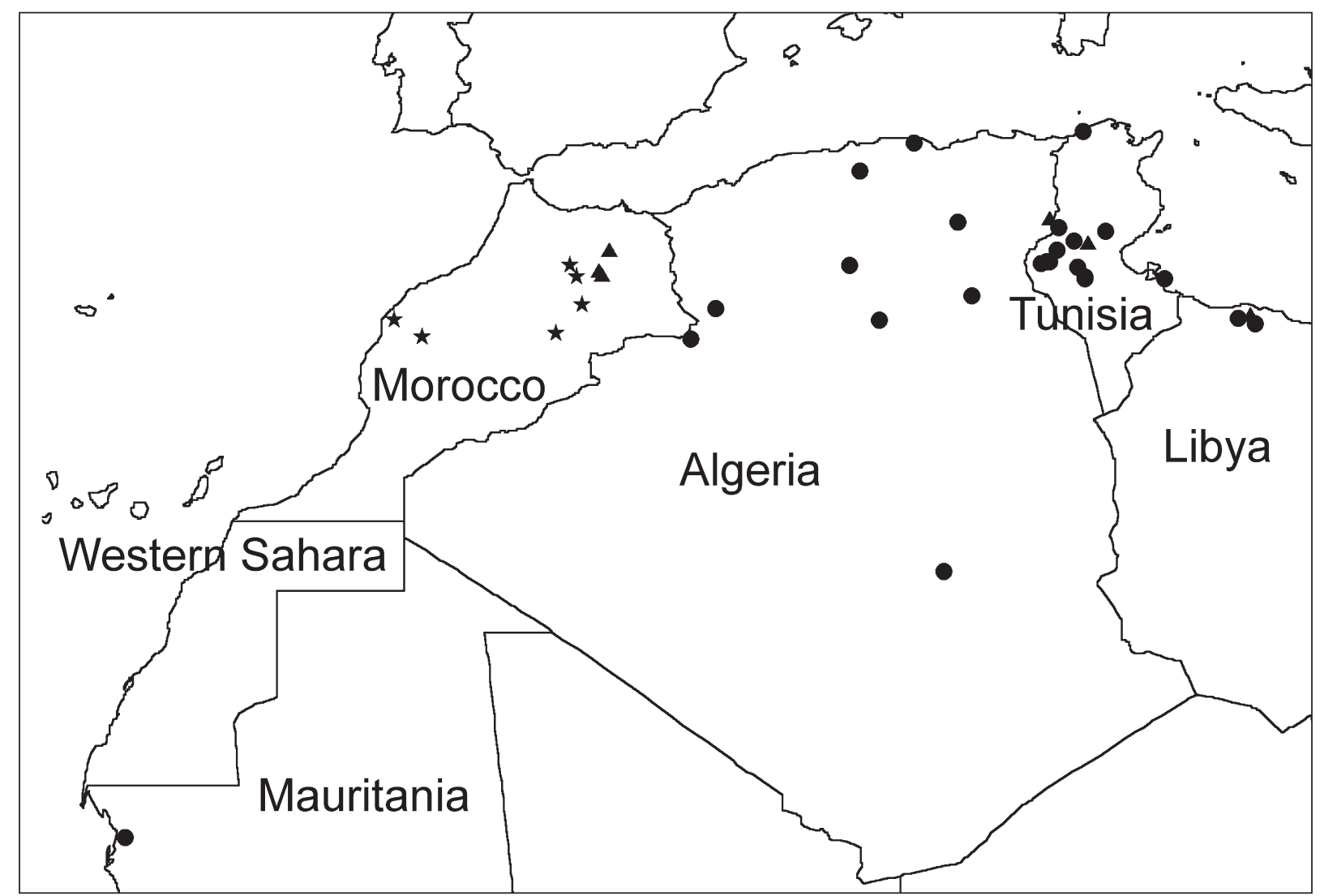

Fig. 10. Distribution of D. chrysoprasis (circles), D. peyerimhoffi (stars) and D. sicardi (triangles).

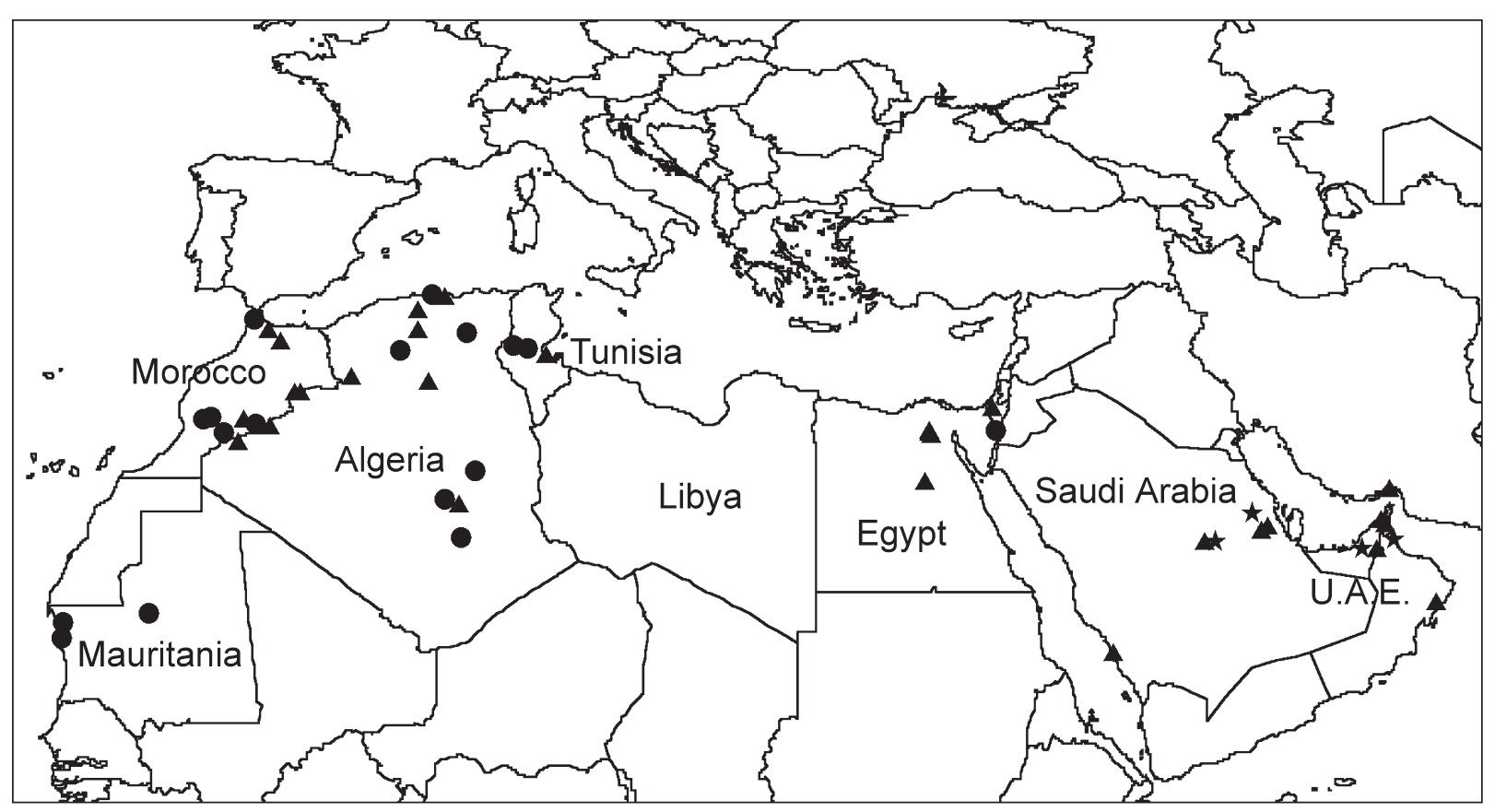

Fig. 11. Distribution of D. hemprichi (triangles), D. obscuritarsis (circles) and D. johnsoni (stars). 


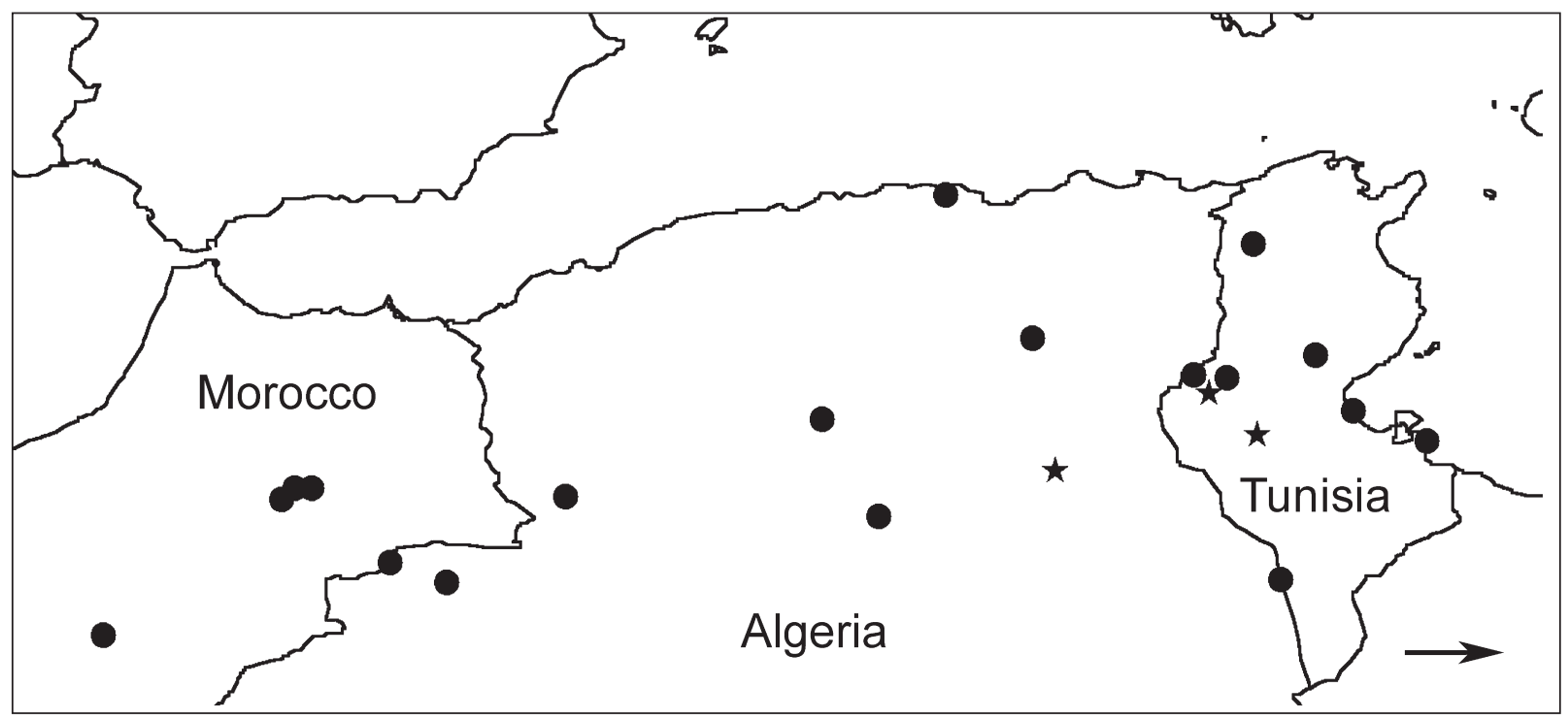

Fig. 12. Distribution of D. promelaena (circles and arrow, which refers to a doubtful record of D. promelaena for Egypt, Sinai) and $D$. carinicollis (stars).

The phylogenetic relationships among the species emerging from the cladistic study, (see "Classification") prompt some biogeographical considerations. The most speciose area results the Western part of Sahara, where are distributed 7 species on 8 (Figs 3-5). One species, D. hemprichi, has a wide Saharao-Sindian distribution, from Atlantic coasts to southern Iran; other species have a wide trans-Saharan range, as D. chrysoprasis, D. obscuritarsis, and possibly also D. promelaena (see "Catalogue"), being spread from Morocco to Egypt. The in-group analysis of two main phyletic lineages suggests the occurrence of late vicariance events, which split these groups in separate areas: (a) In the obscuritarsis group, one species - D. obscuritarsis - is widely distributed, but the remaining two, namely $D$. carinicollis and D. johnsoni, are respectively endemic to the opposite sides of the Sahara-Arabic desert. (b) In the hemprichi group, the robust clade D. sicardi-D. peyerimhoffi, includes one species more spread from Morocco to Tripolitania (D. sicardi) and the second endemic to a narrow area of the Moulouya Valley, in east Morocco.

\section{Acknowledgements}

We wish to thank the following naturalists for the permission to study the Meloidae preserved in their Institutions or private collections and for their help: Claude Girard, Lionel Casset, Jean-
Claude Ringenbach, Paris; Roberto Poggi, Genova; Mauro Bon, Venezia; Otto Merk1, Budapest; Josef Jelinek, Jiři Hajek, Jan Batelka, Praha; Stanislav Krejcik, Unicov, Czech Republic; Ahmed El Hassan and Mohamed Mouna, Rabat; John Pinto, Portland, Oregon, USA.

We also thank Chiara Settanni, Serena Carloni and Andrea Di Giulio (Roma) for their help in the field research. Waleed Hamza of the Al Aïn University kindly supported our research in the United Arab Emirates.

This study was supported by grants from the University "Rome Tre", Department of Biology ("ex 60\%" and "Programmi di ricerca scientifica di rilevante interesse nazionale, n. 99C5271884007') and from the Ministero dell'Istruzione, dell'Università e della Ricerca (coordinator Marco A. Bologna, n. 2004057217). We wish also to acknowledge the financial support of the "European Commission's Research Infrastructure Action via the SYNTHESYS Project", thanks to which researches in some European Museums was carried out by one of us (FT) (FR-TAF44 and HU-TAF-288).

\section{References}

Alfieri A. 1976. The Coleoptera of Egypt. Mémoires de la Société Entomologique d'Egypte 5: XVI + 362 pp.

Batelka J. 2004. Redescription of Diaphorocera carinicollis Chobaut, 1921 (Coleoptera, Meloidae). Bulletin de la Société Entomologique de France 109: 459-460.

Baudi di Selve F. 1878. Meloidae, in: Coleotteri Eteromeri esistenti nelle collezioni del R. Museo Zoologico di Torino ed in altre italiane. Atti della Reale Accademia delle Scienze di Torino 13: 841-866, 1027-1183. 
Bedel L. 1895. Synopsis du genre Diaphorocera Heyd. (1863). L'Abeille 28: 180.

Bedel L. 1917. Diagnoses de Coléoptères nouveaux du Maroc oriental. Bulletin de la Société Entomologique de France 1917: 362-364.

Bologna MA. 1991. Coleoptera Meloidae. Fauna d'Italia. XXVIII. Bologna: Calderini.

Bologna MA, Pinto JD. 2001. Phylogenetic studies of the Meloidae (Coleoptera), with emphasis on the evolution of phoresy. Systematic Entomology 26: 33-72.

Bologna MA, Pinto JD. 2002. The Old World genera of Meloidae (Coleoptera): a key and synopsis. Journal of Natural History 36: 2013-2102.

Bologna MA, Fattorini S, Pinto JD. 2001. Review of the primitive blister beetle genus Iselma with description of the first instar larva (Coleoptera: Tenebrionoidea: Meloidae). African Entomology 9: 105-129.

Chikatunov V. 1999. Catalogue of the beetles (Coleoptera) of Israel and adjacent areas. PhD Thesis, Department of Zoology, George S. Wise Faculty of Life Sciences, Tel Aviv University, $88 \mathrm{pp}$.

Chobaut A. 1921. Description d'un nouveau Diaphorocera (Col. Meloidae) de l'Algérie méridionale. Bulletin de la Société Entomologique de France 1921: 298-299.

Cros A. 1939. Les Meloidae des possessions françaises de l'A frique du Nord - étude biogéographique. Bulletin et Annales de la Société Entomologique de Belgique 79: 247-265.

Di Giulio A, Turco F, Bologna MA. 2002. Larval morphology of the genus Cerocoma and phylogenetic inplications (Coleoptera, Meloidae). Entomologica Fennica 13: 105-112.

Dvořak M. 1989. KORUNOROZCI. Tribus majkovitych brouku CEROCOMINI (Coleoptera, Meloidae, Meloinae). Zpravy Ceskoslovenske Spolecnosti Entomologické pri CSAV 8: 1-20.

Dvořak M. 1996. Ergänzung zum Bestimmungschüssel der Tribus Cerocomini (Coleoptera: Meloidae). Klapalekiana 32: 159-162.

Fairmaire L. 1863. Coléoptères d'Algerie rapportés par M. Ogier de Baulny. Annales de la Société Entomologique de France 3: 637-648.

Fairmaire L. 1875. Coléoptères de la Tunisie récoltés par M. Abdul Kerim. Annali del Museo Civico di Storia Naturale di Genova 7: 475-540.

Fairmaire L. 1876. Diagnoses de Coléoptères du nord de l'Afrique. Petites Nouvelles Entomologiques 151: 49-50.

Fairmaire L. 1882. Coléoptères recueillis par M. G. Révoil chez les Çomalis. In: Mission G. Révoil aux pays Çomalis. Faune et Flore. Paris: Challanel Ainé.

Fairmaire L. 1885. Descriptions de deux Coléoptères algériens. Bulletin de la Société Entomologique de France 1885: 38-39.

Heyden L. 1863. Zwei neue Coleopteren-Gattungen aus dem Mittelmeergebiet. Berliner Entomologischen Zeitschrift 7: 126-130.

Kaszab Z. 1951. Revision der Cerocominen. Acta Biologica Academiae Scientiarum Hungaricae 2: 255-274.

Kaszab Z. 1957. New Meloidae (Coleoptera) from Israel. Bulletin of the Research Council of Israel 6: 229-232.

Kaszab Z. 1969. The system of the Meloidae (Coleoptera). Memorie della Societá Entomologica Italiana 48: 241-248.

Kaszab Z. 1983. Insects of Saudi Arabia - Coleoptera: Fam. Meloidae - A synopsis of the Arabian Meloidae. Fauna of Saudi Arabia 5: 144-204.
Kocher L. 1953. Localisations nouvelles ou intéressantes de Coléoptères Marocains. Travaux de l'Institut Scientifique Chérifien 7: 7-11, 54-59.

Kocher L. 1954. Prospection entomologique (Coléoptères) de la Moyenne Moulouya. Bulletin de la Société de Sciences Naturelles et Physiques du Maroc 34: 263-286.

Kocher L. 1956. Catalogue commenté des Coléoptères du Maroc. Travaux de l'Institut Scientifique Chérifien 5: 1-107.

Kocher L, Reymond A. 1954. Entomologie. In: AA. VV., Les Hamada Sud-Marocains - Résultat de la Mission d'étude 1951 de l'Institut Scientifique Chérifien et du centre de recherches sahariennes. Travaux de l'Institut Scientifique Chérifien 2: 191257.

Normand H. 1938. Contribution au Catalogue des Coléoptères de la Tunisie. Bulletin de la Société d'Histoire Naturelle de l'Afrique du Nord 29: 337-371.

Normand H. 1949. Contribution au Catalogue des Coléoptères de la Tunisie. Bulletin de Science Naturelles de Tunisie 2: 79-104.

Pardo Alcaide A. 1961. XIII. Meloideos del Sahara occidental español y de la region del Drâa (Marruecos) (Coleoptera). EOS, Revista Española de Entomologia 37: 91-111.

Peyerimhoff P. 1931. Mission scientifique du Hoggar envoyée de Février à Mai 1928 par M. Pierre Bordes, Gouverneur Général de l'Algérie. Mémoires de la Société d'Histoire Naturelle de l'Afrique du Nord 2: 1-172.

Pic M. 1897. En route pour le Mzab. - Bou Sàada. Miscellanea Entomologica 5: 124-127.

Pic M. 1900. Enumération d'insectes coléoptères recueillis en orient en 1899. Miscellanea Entomologica 8: 85-86.

Pic M. 1923. Notes diverses, descriptions et diagnoses. (Suite.) L'Echange, Revue Linnéenne 413: 9-11.

Pinto JD, Bologna MA. 1999. The New World Genera of Meloidae (Coleoptera): a key and synopsis. Journal of Natural History 33: 569-619.

Pinto JD, Bologna MA, Bouseman JK. 1996. First-instar larvae, courtship and oviposition in Eletica: amending the definition of the Meloidae (Coleoptera: Tenebrionoidea). Systematic Entomology 21: 63-74.

Schneider W. 1991. New records of Meloidae (Insecta: Coleoptera) from Arabia with description of a new species. Fauna of Saudi Arabia 12: 273-288.

Swofford DL. 2002. PAUP*. Phylogenetic Analysis Using Parsimony (*and Other Methods). Version 4. Massachusetts, Sunderland: Sinauer Associates.

Turco F, Di Giulio A, Bologna MA. 2003. Sexual and cleaning behaviour and related morphology in the genus Cerocoma (Coleoptera: Meloidae). Journal of Insect Behavior 16: 257-278.

Turco F, Di Giulio A, Bologna MA. 2006. The first larval description in the genus Diaphorocera (Coleoptera: Meloidae: Cerocomini): D. chrysoprasis Fairmaire. Zootaxa, 1295: 29-39.

Vigna Taglianti A, Audisio PA, Biondi M, Bologna MA, Carpaneto GM, De Biase A, Fattorini S, Piattella E, Sindaco R, Venchi A, Zapparoli M. 2000. A proposal for a chorotype classification of the Near East fauna, in the framework of the Western Palearctic region. Biogeographia (n.s.) 20: 31-59.

Received: 1 August 2006

Accepted: 23 March 2007 
Appendix 1. Data matrix for the 24 characters used in the phylogenetic analysis.

\begin{tabular}{lccccccccccccccccccccccccc}
\hline & 1 & 2 & 3 & 4 & 5 & 6 & 7 & 8 & 9 & 10 & 11 & 12 & 13 & 14 & 15 & 16 & 17 & 18 & 19 & 20 & 21 & 22 & 23 & 24 \\
\hline OUTGROUP & 1 & 0 & 1 & 1 & 0 & 1 & 0 & 1 & 0 & 1 & 1 & 1 & 0 & 1 & 0 & 0 & 0 & 0 & 0 & 0 & 1 & 0 & 0 & 1 \\
D. hemprichi & 1 & 1 & 0 & 0 & 1 & 1 & 0 & 1 & 1 & 0 & 1 & 1 & 0 & 1 & 0 & 0 & 0 & 0 & 1 & 2 & 0 & 1 & 1 & 0 \\
D. chrysoprasis & 1 & 1 & 0 & 0 & 1 & 1 & 0 & 1 & 1 & 0 & 1 & 1 & 0 & 1 & 0 & 0 & 0 & 0 & 1 & 2 & 0 & 1 & 1 & 0 \\
D. promelaena & 0 & 0 & 0 & 0 & 1 & 0 & 0 & 0 & 0 & 1 & 1 & 1 & 0 & 0 & 0 & 0 & 0 & 1 & 1 & 3 & 0 & 1 & 1 & 1 \\
D. sicardi & 1 & 0 & 1 & 0 & 0 & 1 & 0 & 1 & 1 & 0 & 1 & 0 & 1 & 1 & 1 & 1 & 1 & 1 & 1 & 1 & 0 & 1 & 1 & 0 \\
D. peyerimhoffi & 1 & 0 & 1 & 0 & 0 & 1 & 0 & 1 & 1 & 0 & 1 & 0 & 1 & 1 & 1 & 1 & 1 & 1 & 1 & 1 & 0 & 1 & 1 & $?$ \\
D. obscuritarsis & 0 & 0 & 1 & 1 & 0 & 0 & 1 & 0 & 0 & 0 & 0 & 0 & 0 & 0 & 0 & 0 & 0 & 1 & 0 & 0 & 1 & 1 & 1 & 1 \\
D. johnsoni & 0 & 0 & 0 & 1 & 0 & 0 & 1 & 0 & 0 & 1 & 0 & 0 & 0 & 0 & 0 & 0 & 0 & 1 & 0 & 0 & 1 & 1 & 1 & 1 \\
D. carinicollis & 0 & 0 & 1 & 1 & 0 & 0 & 1 & 0 & 0 & 1 & 0 & 0 & 0 & 0 & 0 & 0 & 0 & 1 & 0 & 0 & 1 & 1 & 1 & 1 \\
\hline
\end{tabular}

Appendix 2. Characters unordered used in the phylogenetic analysis.

\section{Head}

1 Frons between antennal sockets: dark (0), light (1)

2 Maximum length of labrum vs that of clypeus: 1.5 times $\mathrm{X}$ as long (0), twice as long (1)

3 Maximum width on eyes vs that on temples: greater (0), subequal or narrower (1)

4 Posterior margin of frontal calli in dorsal view: reaching the posterior half of eye length $(0)$, reaching the middle of eye length (1)

5 Length of maxillary palpomere IV vs its maximum width: twice as long (0), more than twice as long (1)

6 Length of maxillary palpomere III vs that of segment II: shorter (0), subequal or longer (1)

7 Shape of antennomere XI: elongate (0), subquadrate (1)

8 Colour of antennomere I: dark, at least at base (0), yellow-orange (1)

9 Anterior margin of antennomere IV: bilobate (0), not bilobate (1)

10 Anterior margin of antennomere VII: bilobate (0), not bilobate (1)

11 Frontal calli, in lateral view: slightly visibile (0), evidently visibile (1)

12 Long and light setae on the posterior portion of antennomeres VI-VII: absent (0), present (1)

13 Shape of anterior part of frontal calli: simple (0), raised with two keels apically pointed (1)

Appendix 3. Cladogram statistics for the phylogenetic analysis.

Consistency index (CI)

Homoplasy index (HI)

$\mathrm{CI}$ excluding uninformative characters

HI excluding uninformative characters

Retention index (RI)

Rescaled consistency index (RC)

$$
\begin{aligned}
& =0.7429 \\
& =0.2571 \\
& =0.7273 \\
& =0.2727 \\
& =0.8200 \\
& =0.6091
\end{aligned}
$$

14 Colour of the antero-lateral part of head, anterior to eyes: completely dark ( 0$)$, at least partially yelloworange (1)

15 Shape of distal end of maxillary palpomere III: simple (0), externally pointed (1)

16 Setae on labrum: normal (0), long and lanuginose (1)

17 Labrum with a longitudinal medial area: slightly raised (0), distinctly raised, separated and arcuate (1)

\section{Thorax}

18 Colour of middle and hind trochanters: yellow-orange (0), metallic or black (1)

19 Fore tibiae: simple (0), variously modified (1)

20 Shape of fore tibiae: sub-cylindrical (0), with a basal external short inflated expansion (1), with a laminar external expansion extended to the whole length (2), with a laminar external expansion only at apex (3)

21 Shape of hind tibiae external spur: narrowly spatulate (0), widely spatulate (1)

\section{Abdomen}

22 Number of hooks on aedeagus: one (0), two (1)

23 Number of hooks on endophallus: one (0), two (1)

24 Ratio of lobes of parameres length vs parameres length: less than $0.3(0)$, more than $0.3(1)$ 
